\title{
Information Acquisition in Ostensibly Efficient Markets
}

\author{
Alasdair Brown* \\ University of East Anglia
}

November 18, 2013

${ }^{*}$ School of Economics, University of East Anglia, Norwich, NR4 7TJ. Email: alasdair.brown@uea.ac.uk. I would like to thank Peter Norman Sørensen (the Editor), three anonymous referees, Fabrizio Adriani, Emilio Barucci, Michela Verardo and Fuyu Yang for comments and suggestions regarding this version and earlier versions produced during my $\mathrm{PhD}$. All errors are my own. Part of the research presented in this paper was carried out on the High Performance Computing Cluster supported by the Research and Specialist Computing Support service at the University of East Anglia. 


\begin{abstract}
I use U.K. betting exchange data on Wimbledon tennis matches to investigate the Grossman and Stiglitz (1980) paradox. Risk-free arbitrage opportunities arise frequently during matches (as information arrives and asynchronously shifts prices), but seldom arise before matches (when there is little information to move prices). I find that on the few occasions that arbitrage opportunities do arise before matches, they last substantially longer than average. This suggests, in line with the paradox, that traders neglect to acquire information (i.e. carry out research, or watch markets) if they believe that markets are already efficient. This neglect, in turn, makes markets inefficient.
\end{abstract}

JEL Classification: G02, G12, G14

Keywords: arbitrage opportunities, efficient markets, algorithmic trading, limits to arbitrage

\title{
1 Introduction
}

The informational efficiency of markets relies on traders acquiring and processing information. Yet, traders are unlikely to spend resources acquiring information if they believe that markets are already efficient. Why spend time poring over a balance sheet if the stock price already reflects its contents? Why schmooze a corporate insider if the information they possess is already in the public domain? Why monitor the market if it is unlikely to throw-up a mispricing? In order to gather information, traders must expect to receive some compensation, in the form of trading profits, for their efforts. Without such compensation, traders will not collect information, and markets will be rendered inefficient (Grossman and Stiglitz $(1980)) .^{1}$

In this paper I provide novel evidence, broadly in line with the above paradox, to suggest that traders do indeed cease to collect information when markets are ostensibly efficient.

I analyse Betfair betting exchange trading on the Wimbledon Men's Singles Tennis Championships between 2008 and 2012. Risk-free arbitrage opportunities arise when there are

\footnotetext{
${ }^{1}$ This argument for the impossibility of informationally efficient markets is so persuasive that it was accepted by Fama in the first paragraph of his 1991 survey of market efficiency (p. 1575).
} 
mispricings between two equivalent assets on a player to win a match. There is substantial, almost, natural variation in the efficiency of this market. Arbitrage opportunities arise frequently during matches (as new information arrives and asynchronously shifts prices), but seldom arise before matches (when little or no new information arrives to move prices). Arbitrageurs therefore have good reason to believe that the pre-match market is already efficient, and consequently have less reason to monitor the market at this time. As a result, I find that on the few occasions that arbitrage opportunities do arise before matches, they last substantially and significantly longer than average. This suggests, more generally, that traders will neglect to acquire information (i.e. carry out research, or watch markets) if they believe markets are already efficient. This neglect, in turn, makes markets inefficient.

The absence of comparable evidence in the literature, thus far, is arguably due to two prominent obstacles. Firstly, the relationship between information acquisition and market efficiency is endogenous. It is difficult to establish whether or not traders acquire information in a purportedly efficient market when the efficiency of the market is itself determined by traders' decisions of whether or not to acquire information. Secondly, even if one could overcome this endogeneity hurdle, it is problematic, outside of the laboratory, to actually observe the information acquired by financial market participants.

Undeterred, I believe that my data allow me to partially circumvent both obstacles. The concentration of information arrival during matches creates just the right breeding ground for market inefficiency and arbitrage opportunities: the prices of the two equivalent betting assets seldom respond identically and synchronously to information on the progress of play. Contrast this with the pre-inplay period, when little information arrives to move any of the prices. As a result of this natural variation in the 'conditions' for market efficiency, I can classify the 'inplay' trading period as ostensibly (or ex-ante) inefficient, and the same market prior to play as ostensibly efficient. Once this classification is made, I can then identify the subsequent information acquisition activity of arbitrageurs by counting the number of seconds that each arbitrage opportunity lasts, and compare this duration across ostensibly efficient periods (prior to matches) and ostensibly inefficient periods (during matches). Crucially, if arbitrage opportunities are short-lived, we know that traders are acquiring information: watching the market for mispricings is, after all, the simplest and cheapest form of information acquisition. 
When I observe that arbitrage opportunities last longer prior to matches (when the market throws up fewer inefficiencies), I can reasonably conclude that traders (temporarily) cease to collect information when they believe the market is already efficient.

What are the implications for market efficiency in equilibrium? In a series of further tests, I compare the probability of observing an arbitrage opportunity - and the profit available if such an opportunity presents itself - across pre-inplay and inplay periods. In such an exercise, I am, in effect, assuming the role of the marginal arbitrageur and comparing my expected profits across trading periods if I were to begin trading tomorrow. Consistent with the actions of arbitrageurs offsetting any natural market (in)efficiency, I find that there is little significant difference in the profits to arbitrage across these two periods. Even though arbitrage opportunities arise much less frequently pre-match, the longer duration of the few opportunities that do arise prior to matches means that the market is actually equally (in)efficient across trading periods. In other words, even an ostensibly efficient market (prematch) can become inefficient if traders stop collecting information. This result, I believe, is firmly in the spirit of the Grossman and Stiglitz model.

It must be clarified that Grossman and Stiglitz focused on information acquisition regarding the fundamental value of an asset. Such information acquisition can be interpreted as, for example, analysing a firm's balance sheet, and then evaluating the stock price on the basis of the information garnered. Information acquisition in my setting is more basic, and simply involves monitoring the price of an asset in two markets in search of a mispricing that can be arbitraged. As a result, the arbitrageur is unconcerned about fundamentals, and only concerned with spotting a relative mispricing. Despite these differences in focus, I believe that information acquisition in my setting is analogous to the the type of information acquisition envisaged by Grossman and Stiglitz. Just as Grossman and Stiglitz's trader only acquires information when the expected revenues from trading exceed the cost of information, I propose that the betting exchange arbitrageur will only monitor the market when the expected revenues - which are a function of the probability of finding an opportunity, and the returns on offer if such an opportunity is found - exceed the cost of his or her attention.

I will now outline, in more detail, why I believe that this betting market is uniquely suited among asset markets to such a study of the Grossman and Stiglitz paradox. I construct 
arbitrage strategies by taking a long (short) position on a player in the win market, and a short (long) position in a replicating portfolio constructed in the set market (where there is wagering on the specific final score in sets). These arbitrage strategies are not subject to noise-trader risk (as modelled by De Long et al. (1990) and Shleifer and Vishny (1997)). Once a strategy is implemented, the punter can hold their bets until the end of the match and guarantee a fixed profit. (These strategies are risk-free, unlike the majority of financial market arbitrages, because they do not require an ultimate convergence between two mispriced assets for the arbitrageur to collect their profits). When these opportunities persist, I can therefore argue that this is solely due to traders' imperfect monitoring of markets (i.e. choosing not to acquire information), rather than due to the risk involved in arbitrage or any other confounding factor. ${ }^{2}$ As I mentioned, it is not normally possible for researchers to observe the information acquired by financial market participants - outside of the laboratory - and therefore my inverse proxy for information acquisition (the duration of risk-free arbitrage opportunities) presents a rare chance to empirically verify the reasoning behind the Grossman and Stiglitz paradox.

It should be said, however, that risk-free arbitrage opportunities do also exist in some large financial markets. The 'covered interest parity trade'3 - studied by Akram et al. (2008) - is one such example, and 'triangular arbitrage"4 - studied by Kozhan and Wah Tham (2012) and Ito et al. (2012) - is another. Why not simply study these markets? This brings me to the second aforementioned advantage of my trading environment. There is a clean dichotomy in trading times on this exchange, between pre-match trading and inplay trading. Inplay

\footnotetext{
${ }^{2}$ Perhaps the only risk borne by arbitrageurs on the betting exchange is 'execution risk', as modelled by Kozhan and Wah Tham (2012). This risk arises from the fact that arbitrageurs need to execute more than one trade to complete an arbitrage (even in a simple long/short position), and competing arbitrageurs may snap up the limited supply of one or more of these assets before the arbitrage can be completed profitably. This risk, like noise-trader risk, is likely to deter arbitrage. In Section 5, I will argue that execution risk is more pertinent inplay, and therefore cannot explain the persistence of pre-match arbitrage opportunities.

${ }^{3}$ Covered interest parity involves a short position in a low yield currency and a long position in a high yield currency. The position is 'covered' by a futures contract which exchanges the high yield currency, at maturity, back into the low yield currency.

${ }^{4}$ Triangular arbitrage involves exchanging a currency 1 for a currency 2 , then exchanging currency 2 into a currency 3 , and finally exchanging currency 3 back into currency 1 .
} 
trading throws up many more arbitrage opportunities than pre-match trading, when there is little or no new information to shift prices. In my sample there are more than 12 times as many separate arbitrage opportunities during matches (when I assume Betfair commission of $5 \%$ ), despite pre-match trading making up the majority of trading hours. Most strikingly, only 2 opportunities arose before matches in 2011 (again, when I assume commission of $5 \%)$. This clean dichotomy allows me to compare the duration of arbitrage opportunities (my inverse indicator of the extent to which arbitrageurs are monitoring the market), for the same bets, but across periods when markets are ostensibly efficient (pre-match) and periods when markets are ostensibly inefficient (during the match). There is no particular clustering of information arrival or arbitrage opportunities in foreign exchange markets (see Akram et al. (2008)), either during the week or intra-day, so it is not possible to undertake this type of comparison in that market.

Having outlined the idiosyncracies of this market which facilitate such a study, it is worth stressing the other factors which ensure that my results are externally valid for markets with greater economic value. Betfair is the world's largest betting exchange, with the number of trades comparable to that of the major financial exchanges (Croxson and Reade (2011)). For example, total trading volume on the two-week Wimbledon Championships in 2012 amounted to 900 million GBP, involving 96,000 different traders (Betfair Annual Report 2012). Secondly, trading is conducted via a limit order book, where traders can post liquidity (via limit orders) or consume liquidity (via market orders). This replicates the dominant exchange mechanism for financial assets (Parlour and Seppi (2008)). Finally, the exchange allows for algorithmic trading through its Application Programming Interface. The presence of such technology - which should drive down the cost of monitoring the market - mirrors the roll-out of automated trading on most financial exchanges, and makes the persistence of pre-match arbitrage opportunities all the more striking.

In addition to investigating the Grossman and Stiglitz paradox, this work also contributes to the more recent literature on the effect of limited (costly) attention on asset prices. DellaVigna and Pollet (2009) find that some information from Friday earnings announcements is yet to be incorporated into stock prices until the following Monday. On other weekdays, when attention is arguably greater, information is more quickly reflected in prices. In the 
same vein, Hirshleifer et al. (2009) find that price reactions to earnings announcements are less timely when traders are distracted by a large number of similar announcements. These results imply that there are high Sharpe-ratio strategies left on the table due to limited attention. My paper goes further in two respects. Firstly, I demonstrate that there are infinite Sharpe-ratio strategies (opportunities on the betting exchange are risk-free) left on the table due to the limited attention of traders. Secondly, and more importantly, by analysing the duration of arbitrage opportunities across periods when such opportunities are more/less expected, I assess the reactions of arbitrageurs to the presence/absence of mispricing. The structure of the data on the post-earnings announcement drift - where mispricing cannot be observed in real-time and cannot be arbitraged without risk - does not facilitate an analysis of how arbitrageurs respond to an ostensibly efficient market (and therefore does not allow for an investigation of the Grossman and Stiglitz paradox). Put another way, if an arbitrage opportunity is not immediately apparent to the arbitrageur, and is risky - as is the case with the post-earnings announcement drift - then we cannot reasonably infer the (in)activity of the arbitrageur by looking at the duration of the arbitrage opportunity. ${ }^{5}$

This paper is not the first to identify arbitrage opportunities in betting or prediction markets. Hausch and Ziemba (1990) found (ex-post) cross-track opportunities in horse racing pari-mutuel betting systems. Wolfers and Zitzewitz (2004) found cross-exchange opportunities concerning Californian election betting, and Oliven and Rietz (2004) located single exchange arbitrage opportunities on a U.S. Presidential Election. Marshall (2009) found opportunities - or 'Dutch books' - across bookmaker quotes and across sports, and Franck et al. (2013) found opportunities across bookmakers and the Betfair betting exchange regarding football (soccer) matches. My innovation is to consider the incidence and duration of opportunities across pre-match (no information) and inplay (information) trading periods in sports betting, and therefore look more generally at the dynamic interaction between market efficiency and the incentives to make markets efficient.

This paper builds on work in Brown (2013). In that paper I used Wimbledon tennis

\footnotetext{
${ }^{5}$ My results also provide support for the theoretical work of Hens et al. (2006) - a paper that sits at the intersection of the limits to arbitrage and limited attention literatures - as they propose that finite attention leads to unexploited risk-free arbitrage opportunities.
} 
betting data to demonstrate that limited cognition - specifically, constraints on our ability to process information - leads to mispricing. As information arrives during each match, the mispricing between the win and set markets increases. Much of this increase can be attributed to differences in the frequency with which the two markets are updated in the face of new information. If one market is updated as the match progresses, but not the other, we can argue that traders simply lack the information processing capacity to update both markets in a timely fashion. In the present paper, I focus not on the role that limited cognition plays in the precipitation of mispricing, but instead on the role that limited (costly) attention plays in the persistence of such mispricing. As mispricing arises much more frequently inplay (partly due to the aforementioned information processing constraints), arbitrageurs arguably monitor the market more closely during matches. As a result (it would appear), any mispricing that arises outside of this period lasts much longer. In the course of this analysis, I hope to shed light on the more general question of the (im)possibility of efficient markets when information acquisition is costly.

I structure the remainder of the paper as follows. In Section 2 I provide an example of the arbitrage strategies simulated in this paper. In Section 3 I describe the data, and in Section 4 I outline the analysis. In Section 5 I discuss alternative explanations for the results, and Section 6 concludes. Detailed derivations of the two strategies can be found in the Appendix.

\section{Arbitrage Strategy}

Bets on Betfair, a prominent U.K. betting exchange, can be traded on a player to win a tennis match and also the score, in sets, by which the player wins. Bets take the form of a back bet (where the odds plus stake are returned if the outcome occurs) and a lay bet (where the bettor is liable for the odds if the outcome occurs, but pockets the stake if it does not).

Strategy 1 in this paper involves backing a player to win, and simultaneously laying all the possible set-betting outcomes involved in that player winning. Consider a best-of-five set match. The player can win 3-0, 3-1, 3-2, or lose. Suppose that the back odds on a win are $B_{W}$, and the lay odds on a 3-0 win, 3-1 win, and 3-2 win are $L_{0}, L_{1}$ and $L_{2}$ respectively.

Suppose also, for initial simplicity, that commission is paid on the net winnings from this 
arbitrage. In order to guarantee an equal return, whatever the outcome of the match, an arbitrageur should lay $\frac{B_{W}+1}{L_{0}+1}, \frac{B_{W}+1}{L_{1}+1}$ and $\frac{B_{W}+1}{L_{2}+1}$ units against the player to win 3-0, 3-1 and 3-2 respectively, for every 1 unit backed on the player to win.

In fact, commission is paid on net winnings for each market where the win and set markets are classified separately. The initial commission charged to Betfair customers is $5 \%$, but this can decline to as low as $2 \%$ dependent on the volume of the customer's betting. I denote the commission rate as $c \in[0.02,0.05] .^{6}$

In order to guarantee an identical return no matter the outcome of the match, the arbitrageur should lay $x=\frac{a+(f+z g+z) b}{1-g b}, y=\frac{f+(a+z b+z) g}{1-g b}$ and $z=\frac{h+\frac{(a+f b+f+a g) j}{1-g b}}{1-\frac{((g+1) b(b+1) g) j}{1-g b}}$ against the player to win 3-0, 3-1 and 3-2 respectively - where $a=\frac{B_{W}(1-c)+1}{L_{0}+1-c}, b=\frac{c}{L_{0}+1-c}, f=\frac{B_{W}(1-c)+1}{L_{1}+1-c}$, $g=\frac{c}{L_{1}+1-c}, h=\frac{B_{W}(1-c)+1}{L_{2}+1-c}$ and $j=\frac{c}{L_{2}+1-c}$ - for every $w=1$ unit backed on the player to win. The returns for this arbitrage strategy are $r=\frac{(x+y+z)(1-c)-w}{w+x L_{0}+y L_{1}+z L_{2}}$.

In what follows, I consider the returns to this arbitrage and also the opposite trade, where the set outcomes are backed and the win outcome is laid. I label the latter as Strategy 2. The full proofs for both strategies can be found in the Appendix.

\section{Data}

I obtained data on Betfair betting exchange trading on the second week of matches in the 2008-2012 Wimbledon Men's Singles Tennis Championships. The second week includes the fourth round, quarter-finals, semi-finals, and the final (played, weather-permitting, on the Sunday). Wimbledon - the most high-profile of the four 'grand-slam' events - was chosen because it takes place in the U.K., the home country of the Betfair exchange. This ensures liquidity on the exchange, which is important as I require at least one quote for four different bets for each of the arbitrage strategies. If any of these quotes are missing, I cannot construct an arbitrage trade. Likewise, I chose the second week of each of the five tournaments, as at this stage seeded players are likely to be paired against each other, which heightens the betting interest in these matches. All of the data was purchased from Fracsoft, a third party vendor licensed to market Betfair order book data.

\footnotetext{
${ }^{6}$ More details on the Betfair commission can be found at www.betfair.com/aboutUs/Betfair.Charges/
} 
The full data-set includes second-by-second pricing, in the win and set market, for 68 matches across the 5 years (2 matches were missing from the 2012 data). The data includes trading pre-inplay and trading inplay. Typically, Fracsoft begin collecting pre-inplay pricing data on the morning of each match. This means that there is often more pre-inplay pricing data for those matches scheduled later in the day. I will discuss this issue in Section 5. Inplay trading lasts until one player has won three sets and the match is over, or until a player retires injured.

I constructed the two arbitrage strategies for each player in each match, and therefore my full data-set consists of $\left(68^{*} 2 * 2\right)=272$ separate strategies. Due to the frequency with which the data is sampled, in each of the 5 years there are between 958,000 and 1.5 million seconds in which I could observe an arbitrage opportunity. In fact, over the course of the sample I observe 2704 separate arbitrage opportunities (when commission is assumed to equal $2 \%$ ). Many of these lasted for only one second, but one particular opportunity in 2009 lasted for 3 hours and 35 minutes.

One point to make at this stage is that I stopped collecting inplay data when the player in question lost a set. Once a set is lost there are only two outcomes by which a player could win (3-1 and 3-2). I wanted to retain the same structure to the arbitrage trade across pre-inplay periods - where, of course, there are still three ways by which a player could win - and inplay periods. If I allow for arbitrage when there are only 1 or 2 possible set outcomes, this could bias the results when I examine the duration of the arbitrage opportunities. For example, this would leave the analysis open to the argument that inplay opportunities are shorter-lived because fewer trades need to be made (2 or 3 , rather than 4 ). By keeping the same structure to the arbitrage trade across pre-inplay and inplay trading, I avoid such concerns.

In Figure 1 I illustrate the potential returns to arbitrage strategies 1 and 2 over the course of a day. The day in question is the 8th of July 2012, and the match was the Final of that year between Roger Federer and Andy Murray. In this figure I focus on the strategies related to Andy Murray. Strategy 1 takes a long position on Murray in the win market and a short position in the set market. Strategy 2 reverses those two positions. (A $2 \%$ commission level is assumed at this stage).

This figure provides a comprehensive preview of the results to come in Section 4. Prior 
to the match, when there is little or no new information arriving, there are few price changes and therefore few arbitrage opportunities. To be specific, before the match (which begins at $\mathrm{T}=17723$ on the graph) there are no arbitrage opportunities for strategy 1, and 6 separate opportunities for strategy 2. This, at least, is visible to the naked eye. However, once the match goes inplay, and information begins to arrive (thereby causing price changes in both markets), less visible is that there are 70 separate arbitrage opportunities for strategy 1 , and 48 separate arbitrage opportunities for strategy 2. Not only are there more opportunities inplay, they also offer higher returns (4.9\% in the case of one of the opportunities for strategy 2).

The net result of this pattern of arbitrage opportunities is that an arbitrageur who finds attention costly would deem it reasonable to predominantly focus on the inplay period. The consequence of this course of action - as we can see from the Final - is that the few opportunities that do arise prior to the match last much longer. In Figure 1, one pre-match opportunity for strategy 2 lasts 1026 seconds. The longest opportunity for strategy 2 during the match lasts only 95 seconds. Staying with strategy 2, the median duration of arbitrage opportunities prior to this match is 114.5 seconds, compared to a median duration during the match of just 5 seconds. ${ }^{7}$

This is an opportune time to reveal that Betfair impose a 5 second 'cooling-off' period for all bets lodged during matches. This cooling-off period - which begins when a trader lodges a market order - allows those providing liquidity to cancel their limit order before it is finally matched. The aim is to remove any advantage that certain traders have as a result of witnessing the action earlier (in the stadium or with a faster television feed). The consequence of this rule, for any arbitrage trade, is that the minimum time that a trader could execute the four arbitrage bets (in an automated fashion) would be 5 seconds. ${ }^{8}$ The

\footnotetext{
${ }^{7}$ It should be noted that the probability of observing an arbitrage opportunity for one strategy is negatively affected by whether there is a contemporaneous arbitrage opportunity for the other strategy. For example, when the win bets are overpriced relative to the set bets, you cannot simultaneously have set bets overpriced relative to the win bets. In fact, it can be noticed in Figure 1 that at no stage is there a simultaneous arbitrage opportunity for strategies 1 and 2 .

${ }^{8}$ The fact that some opportunities are taken in less than 5 seconds does not rule out the presence of algorithmic traders. For example, suppose that an opportunity was taken in 3 seconds. Suppose, further,
} 
cooling-off period is not imposed prior to matches. I will take this factor into account - and the fact that it may artificially push up the duration of inplay arbitrage opportunities - in the analysis that follows.

\section{Analysis}

\subsection{Arbitrage Returns}

I begin the formal analysis by comparing arbitrage returns prior to each match with the returns available during each match. The evidence from the Final in 2012 suggests that arbitrage opportunities arise more frequently and offer higher returns during play. In this subsection I will use the full 5 year data-set to examine the breadth of this pattern of results.

Table 1a contains summary statistics on arbitrage returns, for the two strategies, when a commission level of $2 \%$ is assumed. These returns therefore reflect those available to specialist arbitrageurs who have whittled down the level of commission they pay by carrying out regular high-volume trading. It can be observed that in each of the 5 years, and for both of the strategies, the median return is higher inplay than it is pre-inplay. Furthermore, there is positive skewness to these returns, in that the maximum return observed is substantially higher during matches than it is prior to matches. It can also be noted that that there are substantially more separate arbitrage opportunities during matches. Across all 5 years and for both strategies, there are 534 separate opportunities before matches but 2170 opportunities during matches. This is despite the majority of (sampled) trading hours taking place before matches.

One concern at this stage is that I am considering arbitrage returns for only the most regular users of Betfair. Anyone without a substantial discount in the commission level they pay would not be able to pick up these risk-free opportunities. Therefore, in Table 1b I that this was because a 'value' trade (i.e. a mispriced quote) was identified and traded upon at $t=-2$. By the time a series of value trades (i.e. an arbitrage opportunity) emerged at $t=0$, and the algorithmic arbitrageur placed their four bets, the aforementioned value trade was already in motion. Therefore, the arbitrage opportunity disappeared at $t=3$, before the arbitrageur could execute all of their four trades. I will discuss execution risk more generally in Section 5. 
consider the same returns, but this time assume a commission level of 5\%. This is the level paid by a first time visitor to the exchange, and therefore represents the other end of the spectrum. I find a somewhat similar pattern of results. Specifically, I find that median and maximum returns are substantially higher inplay than they are pre-inplay. The difference in the number of separate arbitrage opportunities pre-inplay and inplay is even more stark when a commission level of $5 \%$ is assumed. Across all 5 years and for both strategies, there are 109 separate opportunities before matches but 1321 opportunities during matches.

In Table 2 I assess the significance of any differences in returns between pre-inplay and inplay periods. The top panel is reserved for an assumed commission level of $2 \%$, and the bottom panel presents the same regressions assuming a commission level of 5\%. I regress the arbitrage return available (if the return is greater than 0 ) on an inplay indicator variable and a strategy 1 indicator variable. I do this for each of the 5 years. I find that returns are significantly higher for strategy 2, but, more importantly, are significantly higher (at the $0.1 \%$ level) during matches. ${ }^{9}$ This is the case in all 5 years, if analysed separated, or if the data is pooled (in the final column). If a commission level of $2 \%$ is assumed, available arbitrage opportunities are between $0.32 \%$ and $4.05 \%$ higher during matches. This is a substantial difference given the short time frame of these bets. A similar pattern can be found in the bottom panel, where I assume a commission level of $5 \%$.

Up until this point, I have not considered the cooling-off period for bets placed inplay. It is possible that the highest returns, inplay, arise in the first 5 seconds of an arbitrage, and are removed by liquidity providers before an arbitrageur is able to capitalise. Therefore, in Table 3 I repeat the analysis of Table 2, but this time reclassify the first 5 seconds of an inplay arbitrage opportunity as a mirage. These mirages do not represent an arbitrage opportunity. (Note, pre-match opportunities are unaffected by the cooling-off period). In fact, I find very similar results in Table 3 even after reclassifying the mirages. Arbitrage opportunities offer

\footnotetext{
${ }^{9}$ There is no obvious reason why strategy 2 returns should consistently exceed those of strategy 1 (conditional on there being an arbitrage opportunity), as they appear to in Table 2. Yet, this does mirror similar results in Brown (2013), Table 1. There, win market prices (inferred from the midpoint of the bid-ask spread) tended to exceed the prices of the set market equivalent. This means that a long (short) strategy in the set (win) market will, conditional on there being an arbitrage opportunity, yield higher returns than the opposite strategy.
} 
higher returns in each of the 5 years, and for an assumed commission level of both $2 \%$ and $5 \%$.

\subsection{Arbitrage Opportunity Duration}

In this subsection I compare the duration of arbitrage opportunities across pre-inplay and inplay periods. I hypothesise that because arbitrage opportunities are less likely to arise before matches, and offer lower returns, arbitrageurs are less likely to monitor the market (i.e. collect information) at this time. After all, there is little point watching a market that is, in all likelihood, already efficient. The likely consequence of this imperfect monitoring is that arbitrage opportunities will last longer if they arise prior to matches.

In Tables 4a and 4b I present summary statistics on the duration of arbitrage opportunities. I count the number of consecutive seconds that an arbitrage opportunity is observed (in each strategy, for each player and for both pre-inplay and inplay periods). If a positive arbitrage opportunity is partially taken - i.e. returns diminish but do not fall below zero I categorise this as a persistent arbitrage opportunity. As a result I continue to count the seconds that this opportunity exists until the returns on offer fall to zero (or lower).

Turning to Tables $4 \mathrm{a}$ and $4 \mathrm{~b}$, the median duration is lower during matches than prior to matches. The median duration does not exceed 8 seconds during matches, but can be found as high as 133 seconds (in 2012) prior to matches. Likewise, the maximum duration during matches is 963 seconds (16 minutes and 3 seconds), observed in 2011, but the maximum duration is 12,949 seconds (3 hours, 35 minutes, and 49 seconds) prior to matches (observed in 2009).

One striking result is that throughout Tables $4 \mathrm{a}$ and $4 \mathrm{~b}$ the median duration of inplay arbitrage opportunities is 4-8 seconds. In particular, the majority of these readings are 5 seconds. As mentioned in Section 3, Betfair impose a 5 second cooling-off period for all bets lodged during matches, which means that the minimum time an arbitrage trade can last is 5 seconds. The fact that the median duration appears to coalesce around this time frame suggests that many of these opportunities are taken by automated trading.

It is worth bearing in mind that traders that use the Betfair Application Programming Interface - i.e. trade in an automated fashion - are permitted to sample the odds 60 times 
per minute. This is the same rate at which Fracsoft sample the data. They are then able to place bets at a rate of 100 times per second. If a trader signs up for Full Access, they can sample the odds and place bets an unlimited number of times per minute (subject to their own and Betfair's computing constraints). ${ }^{10}$ It is therefore reasonable to assume that an automated arbitrageur can take a pre-inplay arbitrage opportunity in around 1 second, and an inplay opportunity in 6 seconds (or less with the Full Access service). Nevertheless, in the forthcoming analysis we do not require a precise estimate of the minimum time it takes to complete the arbitrage trade. We can use the duration of inplay opportunities as a benchmark for the time it takes to execute the arbitrage (even allowing for the inflation caused by the cooling-off period inplay), and assess whether pre-inplay opportunities (when monitoring is arguably more patchy) last significantly longer.

In Figure 2, I plot four histograms related to the duration of arbitrage opportunities. All 5 years of data is pooled in this figure. The duration of opportunities is converted into natural logarithms in preparation for the upcoming regression analysis. On the left side of Figure 2 I have the duration of arbitrage opportunities pre-inplay (assuming commissions of $2 \%$ and $5 \%$ ). On the right side there are two corresponding panels for arbitrage opportunities that arise during play. We can see that, prior to matches, the duration is more symmetrically distributed. A kernel density is presented to illustrate this. During play, however, there is a greater degree of positive skewness. Much of the mass of the distribution can be found in the left-hand side, with the majority of inplay opportunities taken very quickly.

In Table 5 I attempt to establish the significance of the results I have just discussed. As the data is pooled for the five years, I estimate heteroskedasticity-consistent standard errors using clustering at the year level. The top panel of Table 5 is reserved for all arbitrage opportunities that arose when the commission level was set at $2 \%$, with the bottom panel containing the same analysis for an assumed commission level of 5\%. The first result to acknowledge is that arbitrage opportunities last longer prior to matches (with significance at the $1 \%$ level). This is the case for both commission levels. In other words, as I hypothesised, it would appear that arbitrageurs are less likely to monitor a market that they have good reason to believe is already efficient.

\footnotetext{
${ }^{10}$ More details can be found here: http://bdp.betfair.com/index.php?option
} 
One concern at this stage is that we have already observed significant differences in returns in pre-inplay and inplay periods. If arbitrageurs are waiting for a larger opportunity - after all, this part of their capital is locked up until the end of the match if they enact an arbitrage trade - this may explain the persistence of pre-match opportunities. In that case, my results would not be due to imperfect monitoring: traders see the opportunity, but are simply waiting for a bigger one. To rule out this possibility, I calculate the average return available with each opportunity and add this to regression 2. (I also add a strategy 1 indicator variable, as used before). Judging by the insignificance of these two new coefficients, I do not, at this stage, have evidence to suggest that arbitrageurs are simply waiting for larger opportunities.

It could be argued, however, that the return on offer has no impact on the persistence of arbitrage opportunities unless traders are actually paying attention. This would imply that the return on offer may have more of an impact on the persistence of an arbitrage opportunity if it arises inplay. To test this, I add an interaction term - between the inplay indicator and the average return of the arbitrage opportunity - to regression 3. I find that opportunities with higher returns are indeed taken more quickly inplay. My rationale for this is that many traders will be subject to a commission level of somewhere between $2 \%$ and 5\%. Therefore, when I assume a $2 \%$ commission level, certain traders will perhaps require returns substantially higher than zero in order for these opportunities to actually be profitable for them. This intuition is given further support when we observe the insignificance of the interaction term for a commission level of 5\% (in the bottom panel of Table 5). For this level of commission, all arbitrage opportunities are profitable for all traders. Here, the magnitude of the return on offer does not seem to impact upon the duration of the arbitrage opportunity.

In the duration analysis thus far I have ignored the cooling-off period for inplay bets. The expected effect of accounting for this cooling-off period is somewhat ambiguous. On the one hand, reclassifying the first 5 seconds of an inplay arbitrage opportunity would appear to strengthen the results in Table 5; all inplay arbitrage opportunities of greater than 5 seconds would be 5 seconds shorter. On the other hand, all inplay arbitrage opportunities of 5 seconds or less would drop out of the sample, thereby removing the shortest of inplay arbitrage opportunities. In Table 6 I replicate the analysis of Table 5 but this time account for 
the 5 second mirages inplay. In fact, I find very similar results. Arbitrage opportunities are shorter-lived inplay, under the assumption of both $2 \%$ and $5 \%$ commission, with significance at the $1 \%$ level in all specifications.

What is driving this result? Is it that longer-lived arbitrage opportunities live much longer prior to matches? Or is it that all opportunities, short- or long-lived, last a fixed amount longer prior to matches? Answering this question will tell us something about the mechanism by which opportunities are taken. If the effect is uniform across the distribution, this would suggest that arbitrageurs always have their computers on, but simply have slower (and cheaper) technology at their disposal which takes X seconds more to execute the arbitrage. On the other hand, if the effect is strongest in the right tail of the distribution (i.e. with the longest lived opportunities), then this would suggest long periods of pre-match market neglect by arbitrageurs.

With this in mind, in Table 7 I display the results of a series of quantile regressions. The natural logarithm of the duration of each arbitrage opportunity (in seconds) is regressed on the inplay indicator, the average return (available with this opportunity), a strategy 1 indicator variable, and an interaction between the inplay indicator and average returns (as in the final regressions of Tables 5 and 6). Coefficients are estimated for the 10th, 25th, 50th, 75th and 90th quantiles, and standard errors are constructed by bootstrapping with 20 replications. The important variable is the inplay indicator, and the extent to which it varies across the distribution. I find that the inplay effect generally increases in magnitude with each quantile, for both $2 \%$ and $5 \%$ commissions. In other words, much of the effect observed in Tables 5 and 6 is driven by long-lived opportunities living much longer pre-inplay than they do during matches. Rather than arbitrageurs simply using slower technology prior to matches, there appear to be long periods of almost abandonment of the market.

I will now proceed to a discussion, and a series of tests, to analyse whether there may be alternative explanations for the shorter duration of arbitrage opportunities during matches. One argument that could be made is that arbitrage opportunities are short-lived during matches not because arbitrageurs are more actively preying on any mispricing, but because volatility in the two prices (in the win and set markets) is much higher during matches (as information arrives). Put another way, volatility eradicates one arbitrage opportunity 
but may then create another. In my analysis this would be considered as two separate short-lived arbitrage opportunities, and therefore perhaps mistakenly support my arbitrageur inattention hypothesis. One solution to this concern is to to compare the duration of arbitrage opportunities across different sections of the pre-inplay trading period. For example, it is possible that arbitrageurs ready themselves for the impending opportunities in the hours before a match starts. This would mean that arbitrage opportunities would be shorterlived the closer you get to the beginning of the match. As the match is yet to begin, the eradication of arbitrage opportunities is unlikely to be due to volatility in the two prices caused by information arrival.

With this in mind, I discarded the inplay data, and set about dividing up the pre-inplay trading window. I created three cut-offs: 30 minutes before play, 60 minutes before play, and 120 minutes before play. If imperfect monitoring of markets is behind the persistence of arbitrage opportunities, we should observe that arbitrage opportunities are shorter-lived in the windows immediately preceding play. What is more, we should observe a stronger effect the closer the window is to the beginning of play, as arbitrageurs are arguably more likely to be active.

In Table 8 I display the results of this analysis. I regress the natural logarithm of the duration of each arbitrage opportunity on an 'after cut-off' indicator variable. This variable equals 1 if trading is in the 30 minute window before play, the 60 minute window before play, or the 120 minute window before play, in regressions 1, 2 and 3 respectively. When I assume commission of $2 \%$, arbitrage opportunities are indeed shorter-lived immediately preceding play. As expected, the effect is strongest the closer we are to play (the absolute magnitude of the coefficient is largest when the cut-off is 30 minutes before play, and smallest when the cut-off is 120 minutes before play). When I assume a commission of $5 \%$ we lose some statistical power. There are only 110 opportunities over 5 years at this level of commission (incidentally, the number of observations may differ across regressions as the cut-off may split some arbitrage opportunities). Nevertheless, a similar pattern emerges. Arbitrage opportunities are, in general, shorter-lived closer to play, and the effect is strongest the closer we are to play. This supports the view that imperfect monitoring of markets is a factor behind the persistence of arbitrage opportunities, in my opinion not just in pre-inplay trading, but 
throughout the data-set.

Another alternative explanation is that arbitrage opportunities persist prior to matches because arbitrageurs lack sufficient capital to fully remove the opportunity. It is true that quoted volumes tend to be higher prior to matches, and therefore more capital is required to fully eradicate an arbitrage opportunity. For example, average volume (at the best back price) to bet on a player to win, in 2012, was GBP 55,581 pre-inplay, but only GBP 25,498 inplay. Seen in this light, it is possible that arbitrage opportunities persist pre-inplay as arbitrageurs are banging at the door but have insufficient capital to fully knock it down.

One way to evaluate this argument is to consider the reaction of traders to the presence of an arbitrage opportunity. If arbitrageurs are equally responsive to opportunities prior to and during play (but simply capital constrained) we should observe a similar propensity to submit an order - in the face of an arbitrage opportunity - whether play has begun or not. With this in mind, in Table 9 I regress an indicator variable equalling 1 if an order was submitted (in either market) on an indicator variable equalling 1 if there was an arbitrage opportunity at the time of the order. A logit specification is used, and data is pooled for the full 5 years. Firstly, as expected, I find that orders increase in the presence of an arbitrage opportunity (regardless of the assumed commission level). Arbitrage opportunities do indeed increase trading activity. In the second regression I add an indicator variable equalling 1 if there was an order in the preceding second (as orders may cluster), and an indicator variable equalling 1 if trading was inplay. The results show that orders do indeed cluster, and increase during matches. The final regression is the most important. In this regression I retain the aforementioned explanatory variables, but also add an interaction between the arbitrage opportunity indicator, and the inplay indicator. This will inform us of whether or not there are differences in the propensity to submit orders - in the presence of an arbitrage opportunity - across pre-inplay and inplay periods. If the coefficient associated with the interaction is positive and significant, this implies that traders are more responsive to arbitrage opportunities if they arise inplay (which fits in with my tale of imperfect monitoring prior to matches). This is indeed the result that I find. Importantly, this holds even after you control for the clustering of orders and the general propensity for more orders during matches. Interestingly, when a $5 \%$ commission is assumed the arbitrage opportunity indicator loses 
its significance. In other words, traders are (almost) unresponsive to arbitrage opportunities unless they materialise inplay.

\subsection{Implications for Market Efficiency}

Grossman and Stiglitz (1980) argued that markets could neither be efficient nor inefficient in equilibrium. If markets were efficient, there would no longer be incentives for traders to acquire (costly) information. Traders would not pay for information if they could earn the same return as a trader that did not pay for the information. Therefore the market price would not incorporate information and would soon cease to be efficient. Once the market was inefficient, however, incentives for information acquisition would reappear, information would be incorporated into prices and the market would be efficient again. And so on.

I have presented evidence to suggest that traders temporarily cease to collect information when they have good reason to believe a market is already efficient, but another empirical implication of the theory is arguably that the market should be, on average, equally efficient across time. In other words, any time-series difference in the frequency with which opportunities arise should be offset by the incentives that this frequency gives to arbitrageurs to monitor the market.

I continue my analysis by testing this hypothesis. I compare the probability of observing an arbitrage opportunity at any single point in time in pre-inplay and inplay periods. In effect, I am assuming the role of the marginal arbitrageur and assessing the probability of finding an arbitrage opportunity if I began trading tomorrow. In Table 10 I regress an indicator variable equalling 1 if there is an arbitrage opportunity (in that second) on the inplay indicator and the strategy 1 indicator. The top panel is reserved for an assumed commission level of $2 \%$ with $5 \%$ commission assumed in the bottom panel. I carry out this regression for all 5 years individually and for the pooled data-set in the final column. The results in Table 10 suggest that arbitrage opportunities are marginally more likely to be observed during matches across the five years. However, as mentioned in Section 3, there is a cooling-off period of 5 seconds for limit order traders; this allows them to cancel their quotes if the match is inplay.

To account for these mirages, in Table 11 I run the same regressions as Table 10, but denote the first 5 seconds of any opportunity that arises inplay as not representing an arbi- 
trage opportunity. For example, a 7 second opportunity inplay would only be considered an opportunity for the last 2 of those seconds, while a similar opportunity pre-inplay would be unaffected. Once I exclude mirages, I find that there is little difference in the probability of observing an arbitrage opportunity pre-inplay and inplay. On balance, an arbitrage opportunity is more likely pre-match when commission is $2 \%$, and is more likely during matches when commission is $5 \%$. The true commission paid by arbitrageurs is probably somewhere in-between.

Perhaps a more appropriate test of market efficiency across trading periods is to compare arbitrage profits. The probability of observing an arbitrage opportunity is important, but the profits that can be made from such opportunities may differ between pre-match and inplay periods. On the one hand, returns, conditional on there being an arbitrage opportunity, are higher during matches (see Section 4.1). On the other hand, quoted volume is greater prior to matches (see the discussion in Section 4.2), so any returns on offer may scale up more easily at this time. To see which effect dominates, I calculate the maximum profit attainable from the best quotes across the 4 bets, for both strategies. Then, in Table 12, I regress the arbitrage profits (truncated at 0) on the inplay indicator variable and the strategy 1 indicator variable, as used in Tables 10 and 11. A tobit regression is used, with left-censoring at 0 (i.e. no arbitrage profits). The results are, in fact, very similar to Table 10. Specifically, arbitrage profits are higher inplay in 3 of the 5 years for a commission level of $2 \%$, and in 4 of the 5 years for a commission level of $5 \%$. As with the earlier analysis, however, we have to account for the inplay mirages. I therefore repeat the analysis of Table 12 in Table 13, but this time reclassify the first 5 seconds of inplay opportunites as mirages (i.e. not genuine arbitrage opportunities). Once this procedure is carried out, arbitrage profits are higher pre-inplay (overall) if we assume commission of $2 \%$, and higher during play (overall) if we assume commission of $5 \%$. As mentioned before, the commission paid by most arbitrageurs is likely somewhere in-between. In short, due to the endogeneity of market efficiency and the incentives to make markets efficient, it appears that no market period is more efficient than another. ${ }^{11}$

\footnotetext{
${ }^{11}$ The coefficient associated with the strategy 1 indicator - in Tables 10-13 - appears to oscillate from negative to positive (and back) from year to year. While in some years a long (short) position in the win
} 
How does this result fit in with the earlier results on the duration of arbitrage opportunities? Why, if pre-inplay and inplay markets are equally efficient, would an arbitrageur monitor the inplay market more closely? The answer to this is that the pre-inplay and inplay markets are equally efficient only because arbitrageurs monitor the inplay market more closely. If arbitrageurs cut back on their inplay activities, the inplay market would become less efficient, thereby creating incentives for others to take their place. Conversely, if arbitrageurs stepped up their pre-inplay activities, others would have less incentive to monitor the market at this time. In other words, the actions of arbitrageurs (almost perfectly) offset any natural market (in)efficiency.

\section{Discussion}

In this paper I have shown that arbitrage opportunities arise more frequently inplay, but persist for longer prior to matches. The net result is that arbitrage profits show no prominent differences between the two periods. Perhaps the most contentious part of the paper is the argument that the persistence of arbitrage opportunities prior to matches is due to traders' imperfect monitoring of markets. In this section I will discuss whether alternative limits to arbitrage, rather than limited (costly) attention, could explain the longer duration of arbitrage opportunities pre-match. I will also discuss measurement error, and a selection issue that may arise in our data.

The first thing to note when looking for alternative limits to arbitrage is that it is not simply the case that we need to find a limit that is present in our trading environment. Crucially, we need to demonstrate that this limit is more salient in pre-match trading than it is in trading during matches. Only if this is the case, can it explain the substantially longer duration of arbitrage opportunities observed prior to matches.

One candidate that perhaps fits this bill is collateral constraints as a limit to arbitrage. This was modelled by Gromb and Vayanos (2002). The idea is that arbitrage is limited by the (set) market is more profitable (i.e. strategy 1), the opposite position (strategy 2) is more profitable in other years. This mirrors the general results regarding the inplay indicator, where the relative (in)efficiency of the pre-inplay/inplay market oscillates from year to year. 
requirement to post collateral in separate markets. With this capital 'locked-up', it cannot be used for other, perhaps larger, opportunities in the future. This is indeed the case for the arbitrage strategies described in this paper. Once the four bets are lodged, the capital used cannot be re-used until the end of the match. Therefore, an arbitrageur may neglect opportunities that arise pre-inplay, in the expectation that larger opportunities will arise during the match. I would expect, however, that if a sufficiently large opportunity turned up pre-inplay, this would (in a real-options sense) compensate the arbitrageur for forgoing future opportunities. However, in Table 5 I do not observe that the magnitude of the return significantly impacts upon the duration of an opportunity, at least not pre-inplay. Instead, the data suggest that costly attention is a more plausible explanation for the differences in the persistence of arbitrage opportunities.

Another explanation, proposed by Kozhan and Wah Tham (2012), is 'execution risk'. That is, an arbitrageur must process more than one trade to complete this arbitrage strategy. With competition among arbitrageurs, and volatile prices, there is a risk that prices may move before the full strategy is completed. This would leave the arbitrageur to close the arbitrage at a guaranteed loss rather than a guaranteed profit. This is pertinent in this environment, as the arbitrageur needs four trades even for these simple strategies. However, execution risk would arguably be greater inplay, as, with information arriving (and perhaps with more arbitrage competition), there is a greater risk that prices will have moved during the enaction of arbitrage. Furthermore, the cooling-off period - present only during matches - means that an apparent arbitrage opportunity may have disappeared before the arbitrageur can execute the four trades. The arbitrageur may have assembled part, but not all, of the arbitrage portfolio, and be forced to hedge out their position at a loss. In other words, execution risk arguably biases against the results that we observe by deterring inplay arbitrage, and therefore increasing the persistence of arbitrage opportunities at this time.

Having discussed alternative limits to arbitrage, I proceed to a discussion of possible measurement error. The premise of this paper is partly founded on the substantial timeseries variation in the frequency with which arbitrage opportunities arise in this market. There are more than 4 times as many separate opportunities during matches than there are prior to matches, if we assume a commission rate of $2 \%$. There are more than 12 times as 
many if we assume a commission rate of $5 \%$. This is at the root of my proposition that an arbitrageur with costly attention will likely focus on the inplay period. However, this may involve measurement error. I only observe an arbitrage opportunity if it exists when the market is sampled (every 1 second). It is possible that arbitrage opportunities, at least pre-inplay (not subject to the cooling-off period), could be taken in less than a second and therefore not show up in the data. I may therefore be underestimating the number of separate arbitrage opportunities that arise pre-match, and therefore over-estimating the extent to which arbitrageurs regard the market as ostensibly efficient in this trading period. Although this is possible, I would argue that the difference in the number of opportunities - pre-match and during matches - is so large as to comfortably absorb any plausible measurement error without bringing into serious question the proposition that arbitrage opportunities arise more frequently prior to matches. Furthermore, independently of my measurements, I would expect that more opportunities would arise inplay. The arrival of information on asset fundamentals sets off changes in prices in the two markets; these price changes are unlikely to be identical on every occasion. Finally, as I have evidence consistent with the idea that traders monitor the market more closely inplay (arbitrage opportunities are shorter-lived at this time), we are arguably underestimating the intrinsic inefficiency of the inplay market rather than the pre-match market.

Moving on, one concern that has arisen with earlier work on limited attention is a possible selection bias. When researchers have found that less information is incorporated into prices on Fridays (e.g. DellaVigna and Pollet (2009) for earnings announcements and Louis and Sun (2010) for merger announcements), they have had to deal with the problem that firm managers have discretion over the scheduling of such announcements. In other words, a manager may schedule bad (or good) news for a Friday, partly because it is perceived as a low attention day. This would mean that the magnitude of the inattention effect could be confounded with other biases related to the speed with which particularly good (or bad) news is incorporated into prices.

While such selection effects are not a concern in my data (the match scheduler has no vested interest in the existence of arbitrage opportunities), there is variation in the length of the pre-inplay periods across matches. For example, those matches scheduled for later in 
the day will still be pre-inplay in the afternoon while earlier matches will have gone inplay. Yet, at least since a roof was added to the Centre Court in 2009, higher-profile matches have tended to be scheduled for later in the day (the roof allows for play up until 11pm). I would argue that high-profile matches are more likely to generate betting interest throughout the day. Therefore, by generating higher attention in pre-inplay periods than might otherwise be the case, I believe that any variation in the scheduling of matches biases against the results that I find.

There is one final point regarding the data that deserves a mention. Fracsoft collect data from the morning on the day of each match, until the end of play. (The time in the morning that data collection begins is itself variable, presumably dependent on when a Fracsoft employee arrives at work). Trading on the outcome of the matches, however, may have begun a day or two earlier, at the stage that the second player won through from the last round and the pairing was confirmed. This means that there is a substantial amount of (exclusively pre-inplay) data that is uncollected by Fracsoft, and therefore unobservable to the econometrician. I would not go as far as to say that the arbitrage opportunities that I find - prior to matches - are the tip of a very large iceberg. However, it would be ironic if I am underestimating the effect that imperfect market monitoring has on the duration of arbitrage opportunities as a result of the imperfect market monitoring by my data providers.

\section{Conclusion}

For asset prices to be efficient, we need information. For information to be acquired, we need incentives for traders. If prices are already efficient, there are no such incentives, and therefore no such efficiency. This is the logic underlying the paradox that Grossman and Stiglitz presented: a paradox that renders market efficiency impossible.

I collected data from a simple market trading bets on tennis match outcomes. This market has two unique features which make it ideal for studying the above intuition. Arbitrage opportunities are risk-free, and therefore we know if traders are monitoring the market (i.e. collecting information) simply by observing how long an arbitrage opportunity lasts. The second key feature of this market is that there is, almost, natural variation in the frequency in 
which opportunities arise. They arise frequently inplay (when information arrives) but seldom pre-inplay (when there is little or no information). This variation allows me to categorise the pre-match period as ostensibly efficient and the inplay period as less so. In line with the paradox, I find evidence to suggest that traders are less likely to acquire information (monitor the market) when the market is ostensibly efficient. The net result, shown in Section 4.3, is that it is difficult to tell the two trading periods apart in terms of efficiency.

Grossman and Stiglitz remarked in their paper that 'efficient markets theorists seem to be aware that costless information is a sufficient condition for prices to fully reflect all available information...they are not aware that it is a necessary condition' (p. 404).

My results support the impression that costless information is a necessary condition for market efficiency. Information acquisition in this trading environment involves nothing more costly than monitoring the market. With an appropriately designed algorithmic trading strategy, this itself involves nothing more than the cost of keeping a computer running. By demonstrating that such trivial costs are enough to deter information acquisition if the market is perceived to be efficient, this paper gives new empirical weight to the impossibility of informationally efficient markets.

\section{References}

- Akram, Q., F., Rime, D., Sarno, L., (2008). Arbitrage in the Foreign Exchange Market: Turning on the Microscope. Journal of International Economics, 78, 237-253.

- Brown, A., (2013). Information Processing Constraints and Asset Mispricing. Economic Journal, forthcoming.

- Croxson, K., Reade, J., J., (2011). Information and Efficiency: Goal Arrival in Soccer Betting. Economic Journal, forthcoming.

- De Long, J., B., Shleifer, A., Summers, L., A., Waldmann, R., J., (1990). Noise Trader Risk in Financial Markets. Journal of Political Economy, 98, 703-738.

- DellaVigna, S., Pollet, J., M., (2009). Investor Inattention and Friday Earnings Announcements. Journal of Finance, 64, 709-749. 
- Fama, E., F., (1991). Efficient Capital Markets: II. Journal of Finance, 46, 1575, 1617.

- Franck, E., Verbeek, E., Nüesch, S., (2013). Inter-Market Arbitrage in Betting. Economica, 80, 300-325.

- Gromb, D., Vayanos, D., (2002). Equilibrium and Welfare in Markets With Financially Constrained Arbitrageurs. Journal of Financial Economics, 66, 361-407.

- Grossman, S., J., Stiglitz, J., E., (1980). On the Impossibility of Informationally Efficient Markets. American Economic Review, 70, 393-408.

- Hausch, D., B., Ziemba, W., T., (1990). Arbitrage Strategies for Cross-Track Betting on Major Horse Races. Journal of Business, 43, 61-78.

- Hens, T., Herings, J., J., Predtetchinskii, A., (2006). Limits to Arbitrage when Market Participation is Restricted. Journal of Mathematical Economics, 42, 556-564.

- Hirshleifer, D., Lim, S., S., Teoh, S., H., (2009). Driven to Distraction: Extraneous Events and Underreaction to Earnings News. Journal of Finance, 64, 2289-2325.

- Ito, T., Yamada, K., Takayasu, M., Takayasu, H., (2012). Free Lunch! Arbitrage Opportunities in the Foreign Exchange Markets. NBER working paper 18541.

- Kozhan, R., Wah Tham, W., (2012). Execution Risk in High-Frequency Arbitrage. Management Science, 58, 2131-2149.

- Louis, H., Sun, A., (2010). Investor Inattention and Market Reaction to Merger Announcements. Management Science, 56, 1781-1793.

- Marshall, B., R., (2009). How Quickly is Temporary Market Inefficiency Removed? Quarterly Review of Economics and Finance, 49, 917-930.

- Oliven, K., Rietz, T., A., (2004). Suckers are Born but Markets are Made: Individual Rationality, Arbitrage, and Market Efficiency on an Electronic Futures Market. Management Science, 50, 336-351. 
- Parlour, C., A., Seppi, D., J., (2008). Limit Order Markets: A Survey. Handbook of Financial Intermediation and Banking, edited by Boot, A., W., A., Thakor, A., V., Elsevier.

- Shleifer, A., Vishny, R., W., (1997). The Limits to Arbitrage. Journal of Finance, 52, $35-55$.

- Wolfers, J., Zitzewitz, E., (2004). Prediction Markets. Journal of Economic Perspectives, 18, 107-126.

\section{Appendix}

\section{Arbitrage Strategies}

\section{Strategy 1}

Recall that the back odds for a win were $B_{W}$, and the lay odds were $L_{0}, L_{1}, L_{2}$ for a 3-0, 3-1, and 3-2 win respectively. Also recall that the commission, $c \in[0.02,0.05]$, is paid on the net winnings in the win market, and the net winnings in the set market. If the player in question loses, then the revenue after commission is $(x+y+z)(1-c)-w$. No commission is paid in the win market as a loss is incurred. If the player wins, then commission is only paid in the win market, as the set markets can be expected to yield a net loss. The revenue after commission is $w B_{W}(1-c)+y+z-x L_{0}, w B_{W}(1-c)+x+z-y L_{1}$ and $w B_{W}(1-c)+x+y-z L_{2}$ for a 3-0, 3-1 and 3-2 win respectively, subject to $y+z-x L_{0}<0, x+z-y L_{1}<0$ and $x+y-z L_{2}<0$ respectively. For our arbitrage we require that the revenue after commission is equal whatever the outcome of the match. After rearranging, $w=1, x=\frac{B_{W}(1-c)+(y+z) c}{L_{0}+1-c}$, $y=\frac{B_{W}(1-c)+(x+z) c}{L_{1}+1-c}$ and $z=\frac{B_{W}(1-c)+(x+y) c}{L_{2}+1-c}$. To solve the three simultaneous equations, define $a=\frac{B_{W}(1-c)+1}{L_{0}+1-c}, b=\frac{c}{L_{0}+1-c}, f=\frac{B_{W}(1-c)+1}{L_{1}+1-c}, g=\frac{c}{L_{1}+1-c}, h=\frac{B_{W}(1-c)+1}{L_{2}+1-c}$ and $j=\frac{c}{L_{2}+1-c}$. This leaves $x=\frac{a+(f+z g+z) b}{1-g b}, y=\frac{f+(a+z b+z) g}{1-g b}$ and $z=\frac{h+\frac{(a+f b+f+a g) j}{1-g b}}{1-\frac{((g+1) b-(b+1) g) j}{1-g b}}$. The collateral required to enact this arbitrage is $w+x L_{0}+y L_{1}+z L_{2}$ so the arbitrage return is $r=\frac{(x+y+z)(1-c)-w}{w+x L_{0}+y L_{1}+z L_{2}}$. 


\section{Strategy 2}

Now suppose that the opposite arbitrage is carried out. The win bet is laid, and the set bets are backed. The lay odds on offer for a win are $L_{W}$, and the back odds are $B_{0}, B_{1}$ and $B_{2}$, for a 3-0, 3-1 and 3-2 win respectively. $w$ will be laid on the win bet, with $x, y$ and $z$ backed on the 3-0, 3-1 and 3-2 win respectively. If the player in question loses then the net revenue after commission is $w(1-c)-x-y-z$. The net revenue after commission is $\left(x B_{0}-y-z\right)(1-c)-w L_{W},\left(y B_{1}-x-z\right)(1-c)-w L_{W}$ and $\left(z B_{2}-x-y\right)(1-c)-w L_{W}$ for a $3-0,3-1$ and 3-2 win respectively. In order to secure a uniform return no matter what the outcome of the match, $w=1, x=\frac{w L_{W}+w(1-c)-(y+z) c}{B_{0}(1-c)+1}, y=\frac{w L_{W}+w(1-c)-(x+z) c}{B_{1}(1-c)+1}$ and $z=\frac{w L_{W}+w(1-c)-(x+y) c}{B_{2}(1-c)+1}$. To solve the three simultaneous equations, set $a=\frac{L_{W}+(1-c)}{B_{0}(1-c)+1}, b=\frac{c}{B_{0}(1-c)+1}, f=\frac{L_{W}+(1-c)}{B_{1}(1-c)+1}$, $g=\frac{c}{B_{1}(1-c)+1}, h=\frac{L_{W}+(1-c)}{B_{2}(1-c)+1}$ and $j=\frac{c}{B_{2}(1-c)+1}$. Then $x=\frac{a-b(f-g z+z)}{1-g b}, y=\frac{f-g(a-b z+z)}{1-g b}$ and $z=\frac{h-\frac{(a-f b+f-a g) j}{1-g b}}{1+\frac{2 b j g-j b-j g}{1-g b}}$. The collateral required to enact this arbitrage is $w L_{W}+x+y+z$ so the return for this strategy is $\frac{w(1-c)-x-y-z}{w L_{W}+x+y+z}$. 


\section{Figures and Tables}

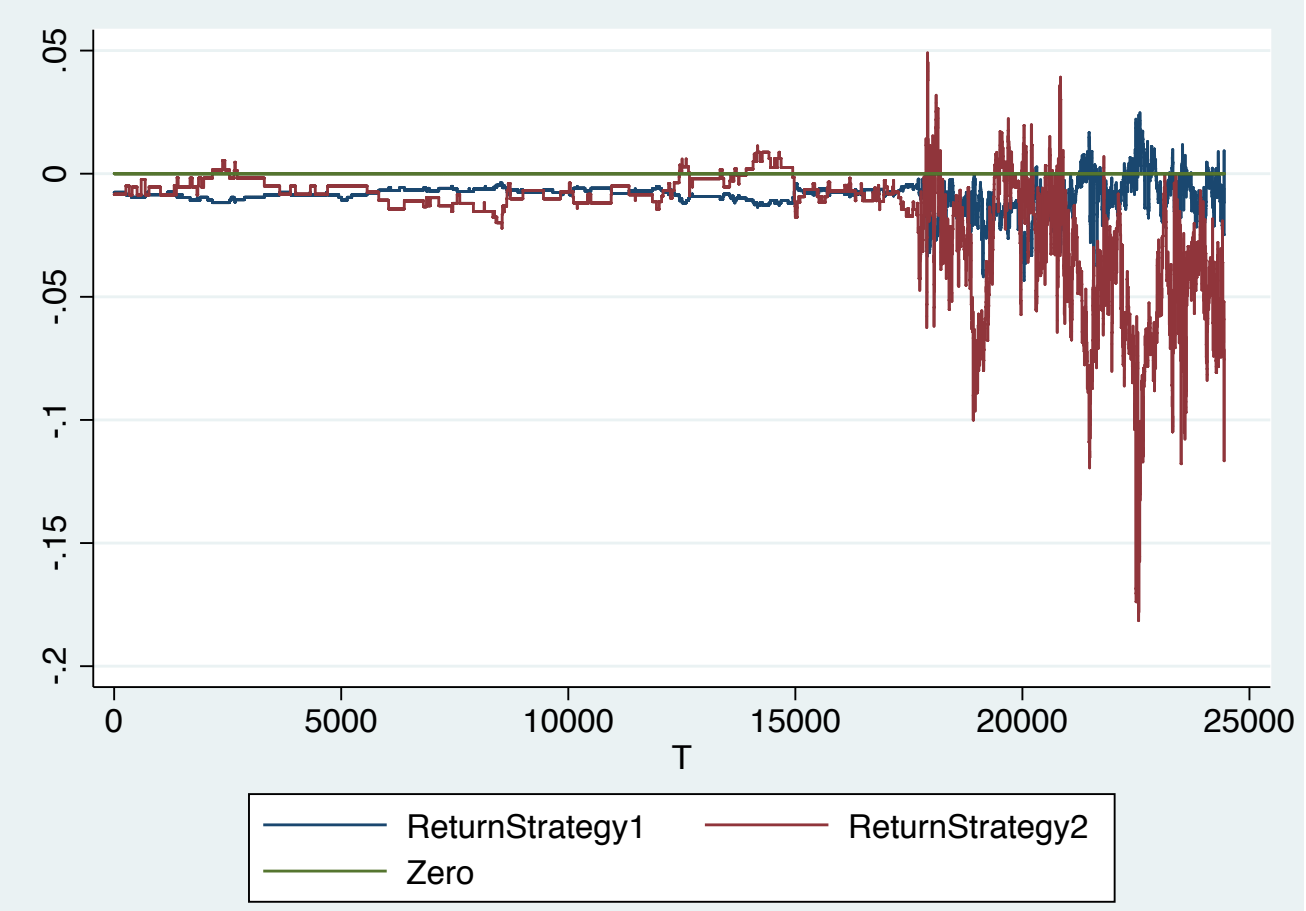

Figure 1: The returns to strategy 1 (blue) and strategy 2 (red) prior to and during the Wimbledon Men's Singles Tennis Championships Final in 2012. The strategies in this graph focus on Andy Murray. Strategy 1 involves a long position on Murray in the win market and a short position in the set market. Strategy 2 is the opposite. A commission of $2 \%$ is assumed here, and the analysis is truncated when Murray loses a set. The match began at 14:10:18 $(\mathrm{T}=17723)$ on the 8th July 2012. 


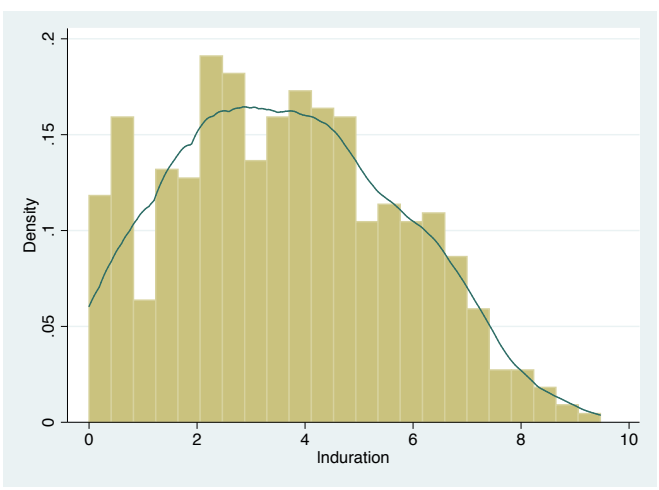

(a) Pre-inplay, $c=2 \%$

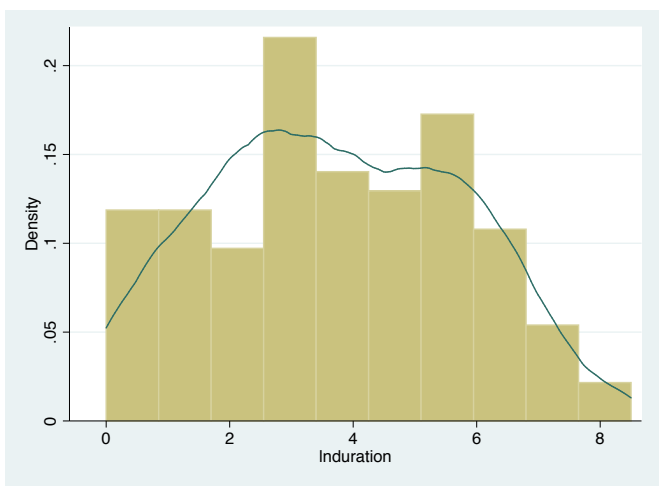

(c) Pre-inplay, $c=5 \%$

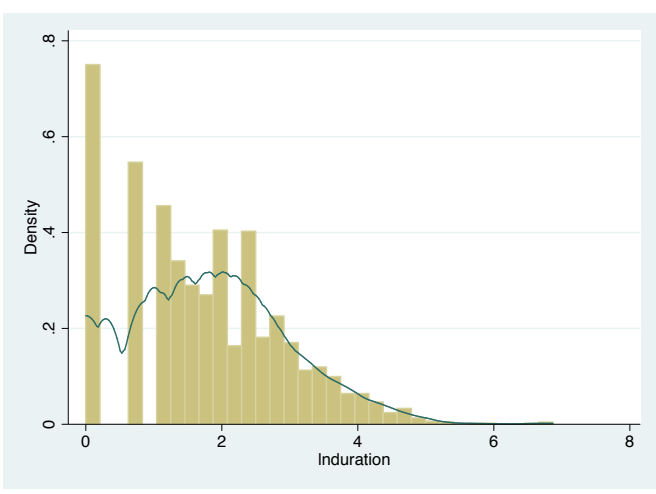

(b) Inplay, $c=2 \%$

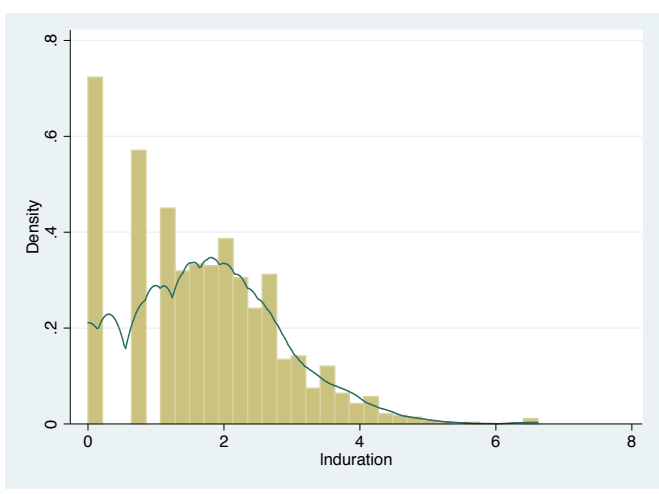

(d) Inplay, $c=5 \%$

Figure 2: Histograms of the natural logarithm of the duration of arbitrage opportunities (in seconds). (a) contains opportunities pre-inplay assuming a commission of $2 \%$, (b) contains opportunities inplay assuming a commission of $2 \%$, (c) contains opportunities pre-inplay assuming a commission of $5 \%$, and (d) contains opportunities inplay assuming a commission of $5 \%$. All histograms are accompanied by a kernel density plot. Data from all 5 years of trading from 2008-2012 is included. 


\begin{tabular}{|c|c|c|c|c|c|c|}
\hline Table 1a: Arbitrage Returns & & & & & & \\
\hline \multicolumn{7}{|l|}{$2 \%$ Commission } \\
\hline \multicolumn{7}{|l|}{ Strategy 1} \\
\hline 2008 & Mean & Std. Dev. & Median & IQR & Maximum & $\mathrm{N}$ \\
\hline Pre Inplay & 0.1777407 & 0.2022536 & 0.09574913 & 0.1720574 & 0.8769625 & 52 \\
\hline Inplay & 0.6808235 & 0.7370487 & 0.4651056 & 0.7478967 & 8.502837 & 457 \\
\hline 2009 & Mean & Std. Dev. & Median & IQR & Maximum & $\mathrm{N}$ \\
\hline Pre Inplay & 0.1723259 & 0.122685 & 0.1874646 & 0.213956 & 0.4492339 & 45 \\
\hline Inplay & 0.3316675 & 0.3702891 & 0.2185464 & 0.3639636 & 2.609453 & 199 \\
\hline 2010 & Mean & Std. Dev. & Median & IQR & Maximum & $\mathrm{N}$ \\
\hline Pre Inplay & 0.1164041 & 0.1145293 & 0.1010191 & 0.1299736 & 0.6533932 & 77 \\
\hline Inplay & 0.5119488 & 0.47762 & 0.3566888 & 0.5965354 & 2.782184 & 248 \\
\hline 2011 & Mean & Std. Dev. & Median & IQR & Maximum & $\mathrm{N}$ \\
\hline Pre Inplay & 0.06074319 & 0.06241015 & 0.04194047 & 0.1021757 & 0.5038943 & 57 \\
\hline Inplay & 1.546154 & 1.965113 & 0.5994786 & 2.129569 & 14.1382 & 304 \\
\hline 2012 & Mean & Std. Dev. & Median & IQR & Maximum & $\mathrm{N}$ \\
\hline Pre Inplay & 0.1146523 & 0.1502438 & 0.07346601 & 0.09935587 & 0.7576451 & 76 \\
\hline Inplay & 0.4797906 & 0.471343 & 0.3381148 & 0.5171205 & 3.722867 & 368 \\
\hline \multicolumn{7}{|l|}{ Strategy 2} \\
\hline 2008 & Mean & Std. Dev. & Median & IQR & Maximum & $\mathrm{N}$ \\
\hline Pre Inplay & 0.7536643 & 0.5729049 & 0.646572 & 0.8747143 & 3.61741 & 66 \\
\hline Inplay & 1.359713 & 1.358147 & 1.117302 & 1.338265 & 10.77122 & 101 \\
\hline 2009 & Mean & Std. Dev. & Median & IQR & Maximum & $\mathrm{N}$ \\
\hline Pre Inplay & 0.317632 & 0.2746638 & 0.1809201 & 0.3809855 & 1.387605 & 69 \\
\hline Inplay & 0.8173965 & 0.9722625 & 0.5981759 & 0.7430993 & 7.300019 & 120 \\
\hline 2010 & Mean & Std. Dev. & Median & IQR & Maximum & $\mathrm{N}$ \\
\hline Pre Inplay & 0.3324136 & 0.2671477 & 0.2320141 & 0.3337607 & 2.435654 & 31 \\
\hline Inplay & 1.635011 & 1.522966 & 1.268756 & 1.636053 & 6.178241 & 21 \\
\hline 2011 & Mean & Std. Dev. & Median & IQR & Maximum & $\mathrm{N}$ \\
\hline Pre Inplay & 0.405001 & 0.2068976 & 0.4540874 & 0.3464417 & 0.7233274 & 42 \\
\hline Inplay & 7.678228 & 10.74144 & 2.023193 & 10.11855 & 63.14021 & 175 \\
\hline 2012 & Mean & Std. Dev. & Median & IQR & Maximum & $\mathrm{N}$ \\
\hline Pre Inplay & 0.334157 & 0.2615305 & 0.2486066 & 0.2160271 & 1.355353 & 19 \\
\hline Inplay & 6.625547 & 10.53863 & 1.715916 & 7.529107 & 68.3123 & 177 \\
\hline
\end{tabular}

Summary statistics on arbitrage returns across 5 years of trading (2008-2012) on the second week of the Wimbledon Men's Singles Tennis Championships. Time periods are divided into pre-inplay (before each match) and inplay (during each match). A commission of $2 \%$ is assumed throughout this table. Strategy 1 involves a long position on each player in the win market, and a short position in a replicating portfolio put together in the set market. Strategy 2 is the opposite, with a short position in the win market and a long position in the set market. $\mathrm{N}$ indicates the number of separate arbitrage opportunities. 


\begin{tabular}{|c|c|c|c|c|c|c|}
\hline Table 1b: Arbitrage Returns & & & & & & \\
\hline \multicolumn{7}{|l|}{$5 \%$ Commission } \\
\hline \multicolumn{7}{|l|}{ Strategy 1} \\
\hline 2008 & Mean & Std. Dev. & Median & IQR & Maximum & $\mathrm{N}$ \\
\hline Pre Inplay & 0.1536827 & 0.1686199 & 0.07255853 & 0.1163049 & 0.5378388 & 12 \\
\hline Inplay & 0.6497522 & 0.7439414 & 0.4498039 & 0.6816156 & 8.257753 & 391 \\
\hline 2009 & Mean & Std. Dev. & Median & IQR & Maximum & $\mathrm{N}$ \\
\hline Pre Inplay & 0.0770262 & 0.0600632 & 0.07460896 & 0.07670519 & 0.2372821 & 18 \\
\hline Inplay & 0.3720665 & 0.3827137 & 0.2669362 & 0.3810498 & 2.273542 & 100 \\
\hline 2010 & Mean & Std. Dev. & Median & IQR & Maximum & $\mathrm{N}$ \\
\hline Pre Inplay & 0.06376117 & 0.05606728 & 0.06404802 & 0.02173228 & 0.2440623 & 9 \\
\hline Inplay & 0.4651331 & 0.4154808 & 0.369713 & 0.5633817 & 2.270205 & 151 \\
\hline 2011 & Mean & Std. Dev. & Median & IQR & Maximum & $\mathrm{N}$ \\
\hline Pre Inplay & 0.1229253 & 0.07016553 & 0.1229253 & 0.1215303 & 0.1836905 & 2 \\
\hline Inplay & 1.767082 & 1.991896 & 1.045333 & 2.516316 & 13.37636 & 194 \\
\hline 2012 & Mean & Std. Dev. & Median & IQR & Maximum & $\mathrm{N}$ \\
\hline Pre Inplay & 0.3240408 & 0.1359515 & 0.2380799 & 0.1998018 & 0.5454246 & 12 \\
\hline Inplay & 0.4419095 & 0.4475736 & 0.2990552 & 0.4954246 & 3.14281 & 205 \\
\hline \multicolumn{7}{|l|}{ Strategy 2} \\
\hline 2008 & Mean & Std. Dev. & Median & IQR & Maximum & $\mathrm{N}$ \\
\hline Pre Inplay & 0.3652133 & 0.2758295 & 0.2424781 & 0.320092 & 1.983157 & 32 \\
\hline Inplay & 1.338406 & 1.603763 & 0.7893067 & 1.4966 & 10.30713 & 64 \\
\hline 2009 & Mean & Std. Dev. & Median & IQR & Maximum & $\mathrm{N}$ \\
\hline Pre Inplay & 0.2828753 & 0.2492014 & 0.2035866 & 0.1913462 & 0.862443 & 15 \\
\hline Inplay & 0.9029488 & 1.185052 & 0.5183257 & 0.6683948 & 5.919915 & 43 \\
\hline 2010 & Mean & Std. Dev. & Median & IQR & Maximum & $\mathrm{N}$ \\
\hline Pre Inplay & 0.5997265 & 0.4948897 & 0.3618884 & 0.1583171 & 1.601569 & 2 \\
\hline Inplay & 1.46929 & 1.478296 & 0.7029526 & 2.143924 & 4.803203 & 15 \\
\hline 2011 & Mean & Std. Dev. & Median & IQR & Maximum & $\mathrm{N}$ \\
\hline Pre Inplay & na & na & na & na & na & 0 \\
\hline Inplay & 10.78079 & 11.18518 & 7.386509 & 12.57924 & 59.95001 & 67 \\
\hline 2012 & Mean & Std. Dev. & Median & IQR & Maximum & $\mathrm{N}$ \\
\hline Pre Inplay & 0.1936728 & 0.2549305 & 0.09536255 & 0.220782 & 1.023833 & 7 \\
\hline Inplay & 9.694544 & 11.60457 & 5.817076 & 13.76419 & 64.69064 & 86 \\
\hline
\end{tabular}

Summary statistics on arbitrage returns across 5 years of trading (2008-2012) on the second week of the Wimbledon Men's Singles Tennis Championships. Time periods are divided into pre-inplay (before each match) and inplay (during each match). A commission of $5 \%$ is assumed throughout this table. Strategy 1 involves a long position on each player in the win market, and a short position in a replicating portfolio put together in the set market. Strategy 2 is the opposite, with a short position in the win market and a long position in the set market. $\mathrm{N}$ indicates the number of separate arbitrage opportunities. 


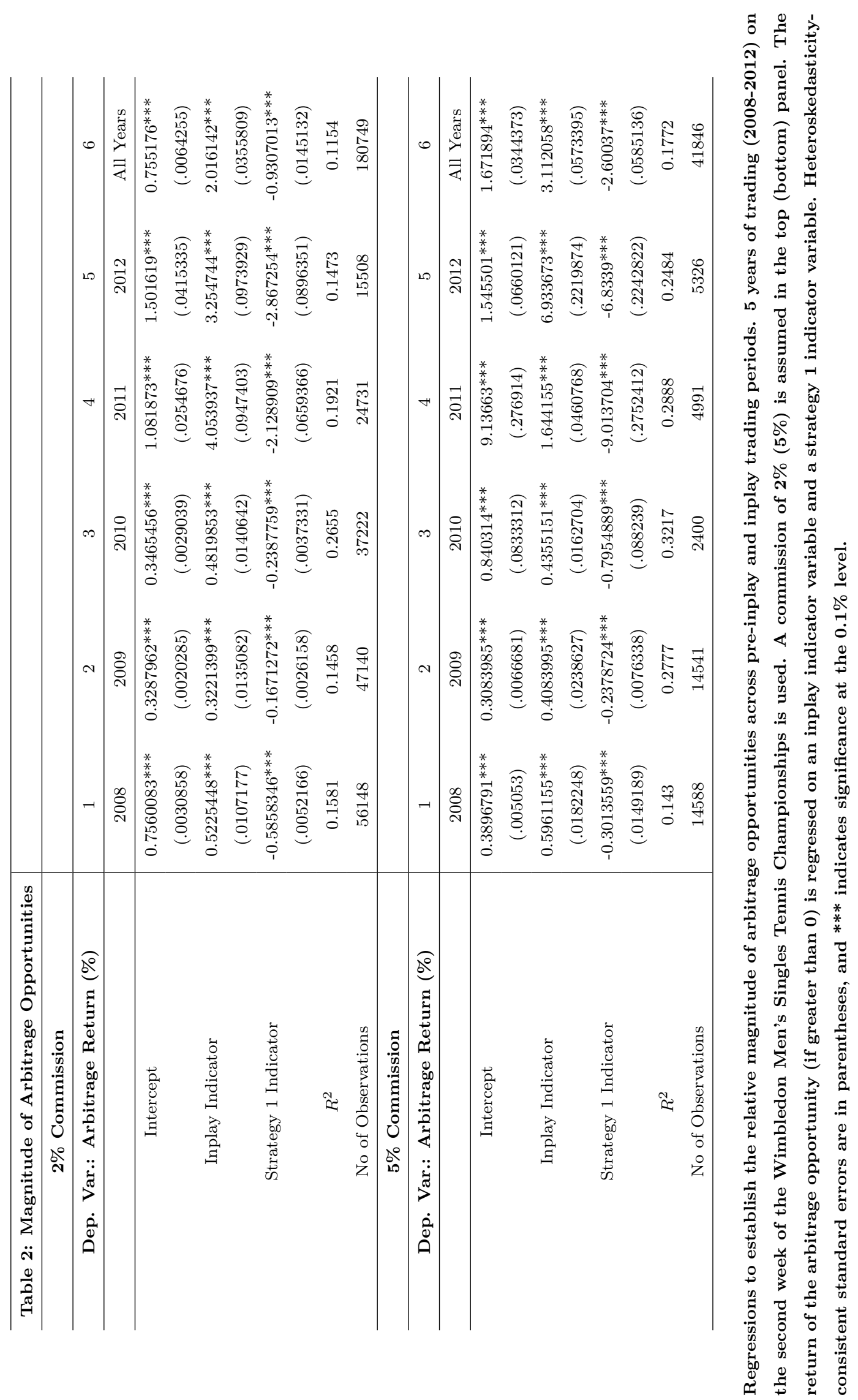




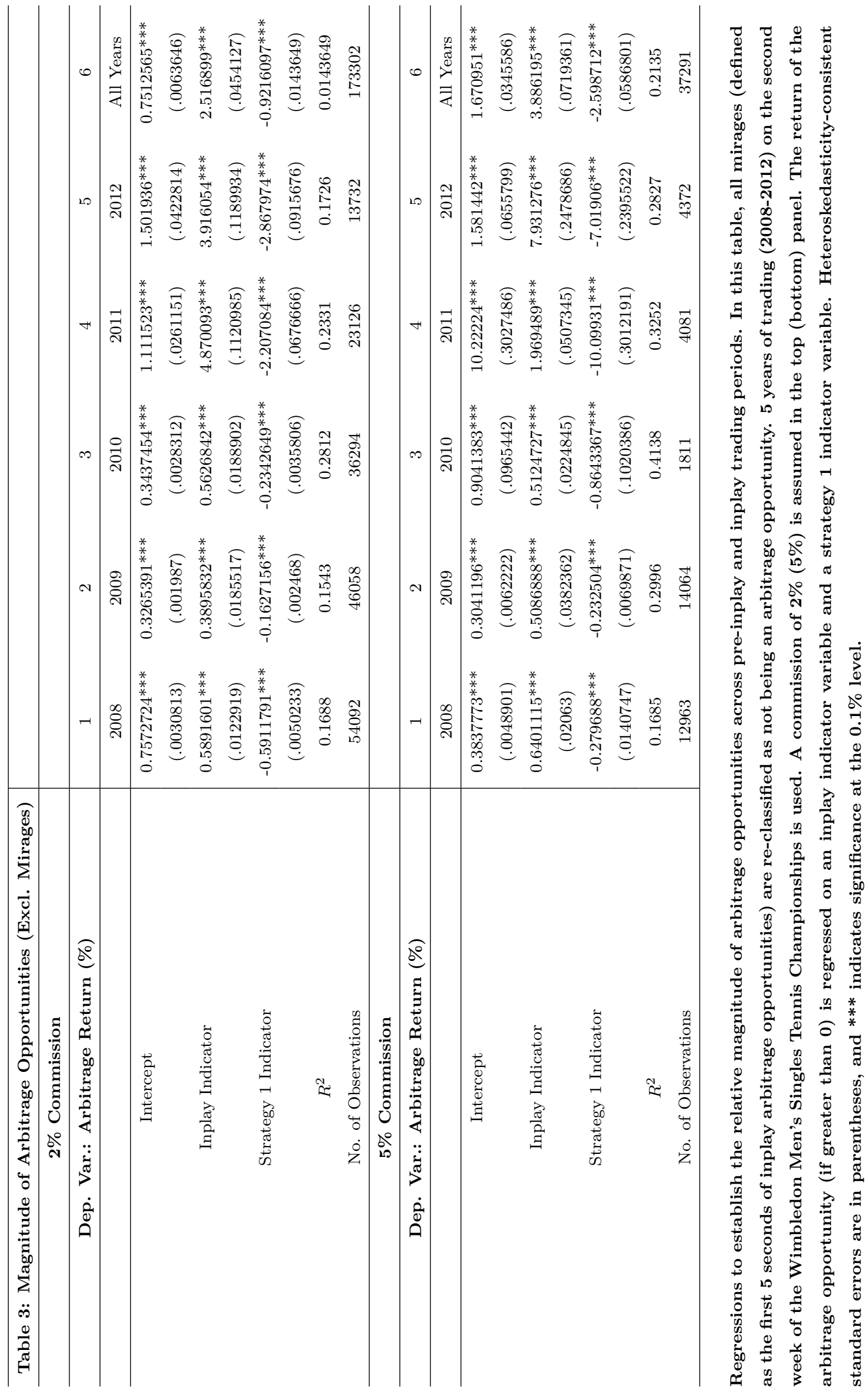




\begin{tabular}{|c|c|c|c|c|c|c|}
\hline Table 4a: Arbitrage Duration (s) & & & & & & \\
\hline \multicolumn{7}{|l|}{$2 \%$ Commission } \\
\hline \multicolumn{7}{|l|}{ Strategy 1} \\
\hline 2008 & Mean & Std. Dev. & Median & IQR & Maximum & $\mathrm{N}$ \\
\hline Pre Inplay & 217.8077 & 363.3321 & 37 & 217.75 & 1435 & 52 \\
\hline Inplay & 15.76586 & 26.03186 & 8 & 15 & 307 & 457 \\
\hline 2009 & Mean & Std. Dev. & Median & IQR & Maximum & $\mathrm{N}$ \\
\hline Pre Inplay & 501.5778 & 1939.288 & 48 & 240 & 12949 & 45 \\
\hline Inplay & 7.944724 & 9.682952 & 5 & 8 & 66 & 199 \\
\hline 2010 & Mean & Std. Dev. & Median & IQR & Maximum & $\mathrm{N}$ \\
\hline Pre Inplay & 279 & 803.9637 & 18 & 73 & 3977 & 77 \\
\hline Inplay & 9.612903 & 15.82148 & 5 & 8 & 125 & 248 \\
\hline 2011 & Mean & Std. Dev. & Median & IQR & Maximum & $\mathrm{N}$ \\
\hline Pre Inplay & 113.2632 & 275.4828 & 16 & 49 & 1423 & 57 \\
\hline Inplay & 16.10526 & 61.98032 & 5 & 10 & 963 & 304 \\
\hline 2012 & Mean & Std. Dev. & Median & IQR & Maximum & $\mathrm{N}$ \\
\hline Pre Inplay & 49.64474 & 94.5662 & 10.5 & 37.5 & 616 & 76 \\
\hline Inplay & 10.76902 & 16.01339 & 5 & 9 & 105 & 368 \\
\hline \multicolumn{7}{|l|}{ Strategy 2} \\
\hline 2008 & Mean & Std. Dev. & Median & IQR & Maximum & $\mathrm{N}$ \\
\hline Pre Inplay & 553.9545 & 1318.329 & 76 & 365.75 & 7443 & 66 \\
\hline Inplay & 10.45545 & 18.46593 & 5 & 10 & 135 & 101 \\
\hline 2009 & Mean & Std. Dev. & Median & IQR & Maximum & $\mathrm{N}$ \\
\hline Pre Inplay & 312.2174 & 709.1228 & 89 & 324 & 5158 & 69 \\
\hline Inplay & 12.04167 & 19.36487 & 5 & 10.25 & 145 & 120 \\
\hline 2010 & Mean & Std. Dev. & Median & IQR & Maximum & $\mathrm{N}$ \\
\hline Pre Inplay & 423.3871 & 650.257 & 109 & 413 & 2700 & 31 \\
\hline Inplay & 10.95238 & 11.236 & 7 & 11 & 44 & 21 \\
\hline 2011 & Mean & Std. Dev. & Median & IQR & Maximum & $\mathrm{N}$ \\
\hline Pre Inplay & 251.5714 & 801.5575 & 27.5 & 61 & 4845 & 42 \\
\hline Inplay & 16.07429 & 69.43748 & 5 & 9 & 899 & 175 \\
\hline 2012 & Mean & Std. Dev. & Median & IQR & Maximum & $\mathrm{N}$ \\
\hline Pre Inplay & 251.7895 & 283.8048 & 133 & 304.5 & 1026 & 19 \\
\hline Inplay & 16.88136 & 58.81638 & 5 & 10 & 725 & 177 \\
\hline
\end{tabular}

Summary statistics on the duration of arbitrage opportunities (in seconds) across 5 years of trading (2008-2012) on the second week of the Wimbledon Men's Singles Tennis Championships. Time periods are divided into pre-inplay (before each match) and inplay (during each match). A commission of $2 \%$ is assumed throughout this table. Strategy 1 involves a long position on each player in the win market, and a short position in a replicating portfolio put together in the set market. Strategy 2 is the opposite, with a short position in the win market and a long position in the set market. $\mathrm{N}$ indicates the number of separate arbitrage opportunities. 


\begin{tabular}{|c|c|c|c|c|c|c|}
\hline Table 4b: Arbitrage D & & & & & & \\
\hline \multicolumn{7}{|c|}{$5 \%$ Commission } \\
\hline \multicolumn{7}{|l|}{ Strategy 1} \\
\hline 2008 & Mean & Std. Dev. & Median & $\mathrm{IQR}$ & Maximum & $\mathrm{N}$ \\
\hline Pre Inplay & 211.75 & 234.6646 & 124 & 280.5 & 645 & 12 \\
\hline Inplay & 12.24552 & 16.70302 & 6 & 11 & 110 & 391 \\
\hline 2009 & Mean & Std. Dev. & Median & IQR & Maximum & $\mathrm{N}$ \\
\hline Pre Inplay & 598.2222 & 1305.055 & 40.5 & 374.25 & 4916 & 18 \\
\hline Inplay & 6.55 & 6.520171 & 4 & 8 & 34 & 100 \\
\hline 2010 & Mean & Std. Dev. & Median & IQR & Maximum & $\mathrm{N}$ \\
\hline Pre Inplay & 110.1111 & 180.9754 & 19 & 58 & 513 & 9 \\
\hline Inplay & 7.910256 & 10.3683 & 5 & 7 & 59 & 156 \\
\hline 2011 & Mean & Std. Dev. & Median & IQR & Maximum & $\mathrm{N}$ \\
\hline Pre Inplay & 2 & 0 & 2 & 0 & 2 & 2 \\
\hline Inplay & 17.0567 & 60.10433 & 6 & 8 & 749 & 194 \\
\hline 2012 & Mean & Std. Dev. & Median & IQR & Maximum & $\mathrm{N}$ \\
\hline Pre Inplay & 30.75 & 55.7366 & 5.5 & 16 & 174 & 12 \\
\hline Inplay & 8.395122 & 11.56122 & 4 & 8 & 75 & 205 \\
\hline \multicolumn{7}{|l|}{ Strategy 2} \\
\hline 2008 & Mean & Std. Dev. & Median & IQR & Maximum & $\mathrm{N}$ \\
\hline Pre Inplay & 212.125 & 392.1861 & 31.5 & 214.25 & 1659 & 32 \\
\hline Inplay & 7.359375 & 7.169971 & 5 & 8.5 & 33 & 64 \\
\hline 2009 & Mean & Std. Dev. & Median & IQR & Maximum & $\mathrm{N}$ \\
\hline Pre Inplay & 182.8 & 247.7427 & 107 & 233 & 979 & 15 \\
\hline Inplay & 8.744186 & 8.91786 & 4 & 10 & 34 & 43 \\
\hline 2010 & Mean & Std. Dev. & Median & IQR & Maximum & $\mathrm{N}$ \\
\hline Pre Inplay & 39 & 21.2132 & 39 & 15 & 54 & 2 \\
\hline Inplay & 6.466667 & 6.906174 & 5 & 7 & 26 & 15 \\
\hline 2011 & Mean & Std. Dev. & Median & IQR & Maximum & $\mathrm{N}$ \\
\hline Pre Inplay & na & na & na & na & na & 0 \\
\hline Inplay & 25.04478 & 91.84348 & 6 & 9.5 & 725 & 67 \\
\hline 2012 & Mean & Std. Dev. & Median & IQR & Maximum & $\mathrm{N}$ \\
\hline Pre Inplay & 218.8571 & 280.1032 & 79 & 325.5 & 719 & 7 \\
\hline Inplay & 19.81395 & 79.46846 & 5 & 9 & 725 & 86 \\
\hline
\end{tabular}

Summary statistics on the duration of arbitrage opportunities (in seconds) across 5 years of trading (2008-2012) on the second week of the Wimbledon Men's Singles Tennis Championships. Time periods are divided into pre-inplay (before each match) and inplay (during each match). A commission of 5\% is assumed throughout this table. Strategy 1 involves a long position on each player in the win market, and a short position in a replicating portfolio put together in the set market. Strategy 2 is the opposite, with a short position in the win market and a long position in the set market. $\mathrm{N}$ indicates the number of separate arbitrage opportunities. 


\begin{tabular}{|c|c|c|c|}
\hline \multicolumn{4}{|l|}{ Table 5: Duration Regressions } \\
\hline \multicolumn{4}{|l|}{$2 \%$ Commission } \\
\hline Dep. Var.: $\ln ($ Duration of Arb. Opp.) & 1 & 2 & 3 \\
\hline Intercept & $\begin{array}{c}3.637129 * * * \\
(.2388844)\end{array}$ & $\begin{array}{c}3.694668 * * * \\
(.2382118)\end{array}$ & $\begin{array}{c}3.207118^{* * *} \\
(.2822125)\end{array}$ \\
\hline Inplay Indicator & $\begin{array}{c}-1.897908^{* *} \\
(.216322)\end{array}$ & $\begin{array}{c}-1.937449^{* *} \\
(.2081333)\end{array}$ & $\begin{array}{c}-1.523748^{* *} \\
(.250508)\end{array}$ \\
\hline Average Returns & & $\begin{array}{l}0.1261278 \\
(.0736231)\end{array}$ & $\begin{array}{c}2.823^{* *} \\
(.4724323)\end{array}$ \\
\hline Strategy 1 Indicator & & $\begin{array}{r}-0.1349142 \\
(.1614518)\end{array}$ & $\begin{array}{l}-0.0316019 \\
(.1713901)\end{array}$ \\
\hline Inplay Indicator*Average Returns & & & $\begin{array}{c}-0.0269874^{* *} \\
(.004822)\end{array}$ \\
\hline$R^{2}$ & 0.2216 & 0.24 & 0.259 \\
\hline No of Observations & 2704 & 2704 & 2704 \\
\hline $5 \%$ Commission & & & \\
\hline Dep. Var.: $\ln ($ Duration of Arb. Opp.) & 1 & 2 & 3 \\
\hline Intercept & $\begin{array}{c}3.698657^{* * *} \\
(.2676672)\end{array}$ & $\begin{array}{c}3.623238^{* * *} \\
(.2482849)\end{array}$ & $\begin{array}{c}3.546491 \\
(.3117313)\end{array}$ \\
\hline Inplay Indicator & $\begin{array}{c}-2.021069^{* *} \\
(.2581429)\end{array}$ & $\begin{array}{l}-2.1174^{* *} \\
(.2801326)\end{array}$ & $\begin{array}{c}-2.046455^{* *} \\
(.3599124)\end{array}$ \\
\hline Average Returns & & $\begin{array}{l}0.1142115 \\
(.0631435)\end{array}$ & $\begin{array}{l}0.5117743 \\
(.5572203)\end{array}$ \\
\hline Strategy 1 Indicator & & $\begin{array}{l}0.1118373 \\
(.1826549)\end{array}$ & $\begin{array}{l}0.1190551 \\
(.1755823)\end{array}$ \\
\hline Inplay Indicator*Average Returns & & & $\begin{array}{l}-0.0039744 \\
(.0058786)\end{array}$ \\
\hline$R^{2}$ & 0.1585 & 0.1908 & 0.1911 \\
\hline No of Observations & 1430 & 1430 & 1430 \\
\hline
\end{tabular}

Regressions to establish the relative duration of arbitrage opportunities in pre-inplay and inplay time periods. 5 years of trading (2008-2012) on the second week of the Wimbledon Men's Singles Tennis Championships are used. The natural logarithm of the duration of each arbitrage opportunity (in seconds) is regressed on an inplay indicator variable in all three regressions. The average return (available with this opportunity), and a strategy 1 indicator variable are added in regression 2. An interaction between the inplay indicator and average returns is added in regression 3. A commission of $2 \%(5 \%)$ is assumed in the top (bottom) panel. Heteroskedasticity-consistent standard errors, clustered for each year, are in parentheses, and *, **, and *** indicates significance at the $5 \%, 1 \%$, and $0.1 \%$ level respectively. 


\begin{tabular}{|c|c|c|c|}
\hline \multicolumn{4}{|l|}{$2 \%$ Commission } \\
\hline Dep. Var.: $\ln$ (Duration of Arb. Opp.) & 1 & 2 & 3 \\
\hline Intercept & $\begin{array}{c}3.637129 * * * \\
(.2389136)\end{array}$ & $\begin{array}{c}3.828227^{* * *} \\
(.2535228)\end{array}$ & $\begin{array}{c}3.341086^{* * *} \\
(.308361)\end{array}$ \\
\hline Inplay Indicator & $\begin{array}{c}-1.603798^{* *} \\
(.2554393)\end{array}$ & $\begin{array}{c}-1.622548^{* *} \\
(.2236702)\end{array}$ & $\begin{array}{c}-1.249753^{* *} \\
(.265627)\end{array}$ \\
\hline Average Returns & & $\begin{array}{l}0.1217348 \\
(.0687482)\end{array}$ & $\begin{array}{c}2.620084^{* *} \\
(.5130055)\end{array}$ \\
\hline Strategy 1 Indicator & & $\begin{array}{l}-0.366015 \\
(.2023576)\end{array}$ & $\begin{array}{l}-0.2085929 \\
(.2139825)\end{array}$ \\
\hline Inplay Indicator*Average Returns & & & $\begin{array}{c}-2.500347^{* *} \\
(.5079685)\end{array}$ \\
\hline$R^{2}$ & 0.1856 & 0.2114 & 0.2335 \\
\hline No. of Observations & 1627 & 1627 & 1627 \\
\hline \multicolumn{4}{|l|}{$5 \%$ Commission } \\
\hline Dep. Var.: $\ln$ (Duration of Arb. Opp.) & 1 & 2 & 3 \\
\hline Intercept & $\begin{array}{c}3.698657^{* * *} \\
(.2677514)\end{array}$ & $\begin{array}{c}3.686366^{* * *} \\
(.2537839)\end{array}$ & $\begin{array}{c}3.636917^{* * *} \\
(.3273062)\end{array}$ \\
\hline Inplay Indicator & $\begin{array}{c}-1.812468^{* *} \\
(.2670679)\end{array}$ & $\begin{array}{c}-1.895837^{* *} \\
(.283658)\end{array}$ & $\begin{array}{c}-1.853378^{* *} \\
(.3712012)\end{array}$ \\
\hline Average Returns & & $\begin{array}{l}0.1145443 \\
(.0658501)\end{array}$ & $\begin{array}{l}0.3605114 \\
(.6050718)\end{array}$ \\
\hline Strategy 1 Indicator & & $\begin{array}{l}-0.0181181 \\
(.2008004)\end{array}$ & $\begin{array}{l}-0.009607 \\
(.1876607)\end{array}$ \\
\hline Inplay Indicator*Average Returns & & & $\begin{array}{l}-0.2457785 \\
(.6254644)\end{array}$ \\
\hline$R^{2}$ & 0.1721 & 0.2076 & 0.2077 \\
\hline No. of Observations & 754 & 754 & 754 \\
\hline
\end{tabular}

Regressions to establish the relative duration of arbitrage opportunities in pre-inplay and inplay time periods. In this table, all mirages (defined as the first 5 seconds of inplay arbitrage opportunities) are re-classified as not being an arbitrage opportunity. 5 years of trading (2008-2012) on the second week of the Wimbledon Men's Singles Tennis Championships are used. The natural logarithm of the duration of each arbitrage opportunity (in seconds) is regressed on an inplay indicator variable in all three regressions. The average return (available with this opportunity), and a strategy 1 indicator variable are added in regression 2 . An interaction between the inplay indicator and average returns is added in regression 3 . A commission of $2 \%(5 \%)$ is assumed in the top (bottom) panel. Heteroskedasticity-consistent standard errors, clustered for each year, are in parentheses, and $*, * *$, and $* * *$ indicates significance at the $5 \%, 1 \%$, and $0.1 \%$ level respectively. 


\begin{tabular}{|c|c|c|c|c|c|}
\hline \multicolumn{6}{|l|}{$2 \%$ Commission } \\
\hline Dep. Var: $\ln$ (Duration of Arb. Opp.) & 1 & 2 & 3 & 4 & 5 \\
\hline Quantile: & 10 & 25 & 50 & 75 & 90 \\
\hline Intercept & $\begin{array}{c}0.6873704^{* * *} \\
(.134268)\end{array}$ & $\begin{array}{c}1.79127^{* * *} \\
(.2077909)\end{array}$ & $\begin{array}{c}2.842111^{* * *} \\
(.1757841)\end{array}$ & $\begin{array}{c}4.349424^{* * *} \\
(.1456903)\end{array}$ & $\begin{array}{c}5.630287^{* * *} \\
(.1904505)\end{array}$ \\
\hline Inplay Indicator & $\begin{array}{c}-0.696067^{* * *} \\
(.1337078)\end{array}$ & $\begin{array}{c}-1.100311^{* * *} \\
(.1818878)\end{array}$ & $\begin{array}{c}-1.30012^{* * *} \\
(.1636531)\end{array}$ & $\begin{array}{c}-2.130481^{* * *} \\
(.1746342)\end{array}$ & $\begin{array}{c}-2.894036^{* * *} \\
(.2563499)\end{array}$ \\
\hline Average Returns & $\begin{array}{l}0.0323177 \\
(1.338063)\end{array}$ & $\begin{array}{l}2.316249 . \\
(1.213985)\end{array}$ & $\begin{array}{c}4.570638^{* * *} \\
(.8781181)\end{array}$ & $\begin{array}{c}4.239601 * * * \\
(.7551563)\end{array}$ & $\begin{array}{c}4.114369 * * * \\
(1.085615)\end{array}$ \\
\hline Strategy 1 & $\begin{array}{l}0.0043985 . \\
(.0026155)\end{array}$ & $\begin{array}{c}-0.0101747 \\
(.125228)\end{array}$ & $\begin{array}{l}0.0552283 \\
(.0782146)\end{array}$ & $\begin{array}{l}0.1512121 \\
(.0938382)\end{array}$ & $\begin{array}{c}0.2407077^{*} \\
(.1015282)\end{array}$ \\
\hline Inplay Indicator*Average Returns & $\begin{array}{l}0.0142602 \\
(1.341648)\end{array}$ & $\begin{array}{l}-2.164113 . \\
(1.214878)\end{array}$ & $\begin{array}{c}-4.341179 * * * \\
(.872295)\end{array}$ & $\begin{array}{c}-3.943193^{* * *} \\
(.7565732)\end{array}$ & $\begin{array}{c}-3.559313^{* * *} \\
(1.128786)\end{array}$ \\
\hline Pseudo $R^{2}$ & 0.0357 & 0.053 & 0.1038 & 0.2031 & 0.305 \\
\hline No. of Observations & 2704 & 2704 & 2704 & 2704 & 2704 \\
\hline \multicolumn{6}{|l|}{ 5\% Commission } \\
\hline Dep. Var: $\ln$ (Duration of Arb. Opp.) & 1 & 2 & 3 & 4 & 5 \\
\hline Quantile: & 10 & 25 & 50 & 75 & 90 \\
\hline Intercept & $\begin{array}{l}0.6726568 . \\
(.4050236)\end{array}$ & $\begin{array}{c}2.082546^{* * *} \\
(.4692517)\end{array}$ & $\begin{array}{c}3.491084^{* * *} \\
(.4518402)\end{array}$ & $\begin{array}{c}5.193813^{* * *} \\
(.4594393)\end{array}$ & $\begin{array}{l}5.60624^{* * *} \\
(.3832275)\end{array}$ \\
\hline Inplay Indicator & $\begin{array}{c}-0.6874563 . \\
(.4072498)\end{array}$ & $\begin{array}{c}-1.413984^{* *} \\
(.4681873)\end{array}$ & $\begin{array}{c}-2.138925^{* * *} \\
(.4634235)\end{array}$ & $\begin{array}{c}-3.146144^{* * *} \\
(.444464)\end{array}$ & $\begin{array}{c}-3.112465^{* * *} \\
(.3947603)\end{array}$ \\
\hline Average Returns & $\begin{array}{l}0.5312735 \\
(1.361519)\end{array}$ & $\begin{array}{l}-0.0613742 \\
(1.600961)\end{array}$ & $\begin{array}{l}-0.1249288 \\
(1.374703)\end{array}$ & $\begin{array}{c}1.440564 \\
(2.394593)\end{array}$ & $\begin{array}{l}2.772865 . \\
(1.495074)\end{array}$ \\
\hline Strategy 1 & $\begin{array}{l}0.0106147 \\
(.0069279)\end{array}$ & $\begin{array}{l}0.0181929 \\
(.0658597)\end{array}$ & $\begin{array}{l}0.2277744^{*} \\
(.0888405)\end{array}$ & $\begin{array}{l}0.2107957^{*} \\
(.1023519)\end{array}$ & $\begin{array}{c}0.4564392^{* * *} \\
(.1234522)\end{array}$ \\
\hline Inplay Indicator*Average Returns & $\begin{array}{l}-0.4809082 \\
(1.363019)\end{array}$ & $\begin{array}{l}0.1502086 \\
(1.595642)\end{array}$ & $\begin{array}{l}0.3704047 \\
(1.392939)\end{array}$ & $\begin{array}{l}-1.171139 \\
(2.388801)\end{array}$ & $\begin{array}{c}-2.40431 \\
(1.488348)\end{array}$ \\
\hline Pseudo $R^{2}$ & 0.0214 & 0.0343 & 0.0626 & 0.1385 & 0.2443 \\
\hline No. of Observations & 1430 & 1430 & 1430 & 1430 & 1430 \\
\hline
\end{tabular}

Regressions to establish whether the longer life of pre-inplay arbitrage opportunities is predominantly due to long, or short, lived opportunities living longer pre-inplay. 5 years of trading (2008-2012) on the second week of the Wimbledon Men's Singles Tennis Championships are used. The natural logarithm of the duration of each arbitrage opportunity (in seconds) is regressed on an inplay indicator variable, the average return (available with this opportunity), a strategy 1 indicator variable, and an interaction between the inplay indicator and average returns. A Quantile specification is used, with estimation at the 10th, 25th, 50th, 75th and 90th quantiles. A commission of $2 \%(5 \%)$ is assumed in the top (bottom) panel. Standard errors, bootstrapped with 20 replications, are in parentheses, and ., *,**, and $* * *$ indicates significance at the $10 \%, 5 \%, 1 \%$, and $0.1 \%$ level respectively. 


\begin{tabular}{|c|c|c|c|}
\hline \multicolumn{4}{|l|}{$2 \%$ Commission } \\
\hline Dep. Var.: $\ln$ (Duration of Arb. Opp.) & 1 & 2 & 3 \\
\hline Cut-Off (minutes before match starts) & 30 mins & 60 mins & 120 mins \\
\hline \multirow[t]{2}{*}{ Intercept } & $4.258721^{* * *}$ & $4.381577^{* * *}$ & $4.384483^{* * *}$ \\
\hline & $(.177828)$ & $(.1649222)$ & $(.2197189)$ \\
\hline \multirow[t]{2}{*}{ After Cut-Off Indicator } & $-1.62807^{* *}$ & $-1.433167^{* *}$ & $-1.217515^{* *}$ \\
\hline & $(.2630808)$ & $(.1846274)$ & $(.1998848)$ \\
\hline$R^{2}$ & 0.1411 & 0.1183 & 0.0816 \\
\hline No. of Observations & 542 & 546 & 543 \\
\hline \multicolumn{4}{|l|}{ 5\% Commission } \\
\hline Dep. Var.: $\ln$ (Duration of Arb. Opp.) & 1 & 2 & 3 \\
\hline Cut-Off (minutes before match starts) & 30 mins & 60 mins & 120 mins \\
\hline \multirow[t]{2}{*}{ Intercept } & $4.102521^{* * *}$ & $4.113271^{* * *}$ & $3.750951^{* * *}$ \\
\hline & $(.2260444)$ & $(.2136703)$ & $(.3911194)$ \\
\hline \multirow[t]{2}{*}{ After Cut-Off Indicator } & -1.314632 & -0.9886269 & -0.0351327 \\
\hline & $(.4735143)$ & $(.3761628)$ & $(.7571032)$ \\
\hline$R^{2}$ & 0.0862 & 0.0575 & 0.0001 \\
\hline No. of Observations & 110 & 112 & 111 \\
\hline
\end{tabular}

Regressions to establish the relative duration of arbitrage opportunities across pre-inplay periods. 5 years of trading (2008-2012) on the second week of the Wimbledon Men's Singles Tennis Championships are used. The natural logarithm of the duration of each arbitrage opportunity (in seconds) is regressed on an after cut-off indicator variable. This indicator variable equals 1 if trading is in the last 30 mins before the match starts, the last 60 mins before the match starts, and the last 120 minutes before a match starts (in regressions 1,2 and 3 respectively). A commission of $2 \%(5 \%)$ is assumed in the top (bottom) panel. Heteroskedasticity-consistent standard errors, clustered for each year, are in parentheses, and ., *,**, and *** indicates significance at the $10 \%, 5 \%, 1 \%$, and $0.1 \%$ level respectively. 


\begin{tabular}{|c|c|c|c|}
\hline 2\% Commission & & & \\
\hline Dep. Var.: Order Indicator & 1 & 2 & 3 \\
\hline Intercept & $\begin{array}{c}-2.026852^{* * *} \\
(.0018026)\end{array}$ & $\begin{array}{c}-2.800877^{* * *} \\
(.0026032)\end{array}$ & $\begin{array}{c}-2.79425^{* * *} \\
(.0026267)\end{array}$ \\
\hline Arbitrage Opportunity Indicator & $\begin{array}{c}0.5384162^{* * *} \\
(.0063301)\end{array}$ & $\begin{array}{c}0.4714188^{* * *} \\
(.0071179)\end{array}$ & $\begin{array}{c}0.392719^{* * *} \\
(.0089356)\end{array}$ \\
\hline Order Indicator $(\mathrm{t}-1)$ & & $\begin{array}{c}1.372795^{* * *} \\
(.0045778)\end{array}$ & $\begin{array}{c}1.371301^{* * *} \\
(.0045848)\end{array}$ \\
\hline Inplay Indicator & & $\begin{array}{c}1.868048^{* * *} \\
(.0042511)\end{array}$ & $\begin{array}{c}1.851339^{* * *} \\
(.0043855)\end{array}$ \\
\hline Arbitrage Opportunity Indicator*Inplay Indicator & & & $\begin{array}{c}0.2528718^{* * *} \\
(.0160152)\end{array}$ \\
\hline Pseudo $R^{2}$ & 0.0028 & 0.1901 & 0.1902 \\
\hline No. of Observations where Dep. Var. $==1$ & 690625 & 690625 & 690625 \\
\hline No. of Observations & 3172631 & 3172631 & 3172631 \\
\hline \multicolumn{4}{|l|}{$5 \%$ Commission } \\
\hline Dep. Var.: Order Indicator & 1 & 2 & 3 \\
\hline Intercept & $\begin{array}{c}-2.010082^{* * *} \\
(.0017509)\end{array}$ & $\begin{array}{c}-2.773967^{* * *} \\
(.0025388)\end{array}$ & $\begin{array}{c}-2.76942^{* * *} \\
(.0025428)\end{array}$ \\
\hline Arbitrage Opportunity Indicator & $\begin{array}{c}1.061349^{* * *} \\
(.011037)\end{array}$ & $\begin{array}{c}0.3848507^{* * *} \\
(.0126527)\end{array}$ & $\begin{array}{l}0.0048295 \\
(.0248449)\end{array}$ \\
\hline Order Indicator $(\mathrm{t}-1)$ & & $\begin{array}{c}1.384676^{* * *} \\
(.0045734)\end{array}$ & $\begin{array}{l}1.38286^{* * *} \\
(.0045775)\end{array}$ \\
\hline Inplay Indicator & & $\begin{array}{c}1.851942^{* * *} \\
(.004249)\end{array}$ & $\begin{array}{c}1.840755^{* * *} \\
(.004293)\end{array}$ \\
\hline Arbitrage Opportunity Indicator*Inplay Indicator & & & $\begin{array}{c}0.5943285^{* * *} \\
(.0303885)\end{array}$ \\
\hline Pseudo $R^{2}$ & 0.0033 & 0.1888 & 0.189 \\
\hline No. of Observations where Dep. Var. $==1$ & 690625 & 690625 & 690625 \\
\hline No. of Observations & 3172631 & 3172631 & 3172631 \\
\hline
\end{tabular}

Regressions to establish whether traders are more likely to respond to arbitrage opportunities (by submitting orders) if such an opportunity arises inplay. 5 years of trading (2008-2012) on the second week of the Wimbledon Men's Singles Tennis Championships are used. An indicator variable equalling 1 if an order was placed in the last second (in either market) is regressed on an indicator variable equalling 1 if there was an arbitrage opportunity at the time of the order. An indicator for orders in the previous second (to handle order clustering) and an indicator for inplay trading are added in regression 2. In regression 3 , an interaction between the arbitrage opportunity indicator and the inplay indicator is added to capture any differences in the propensity to react to arbitrage opportunities inplay versus pre-inplay. A commission of $2 \%(5 \%)$ is assumed in the top (bottom) panel. A logit specification is used, heteroskedasticity-consistent standard errors, clustered for each year, are in parentheses, and $* * *$ indicates significance at the $0.1 \%$ level. 


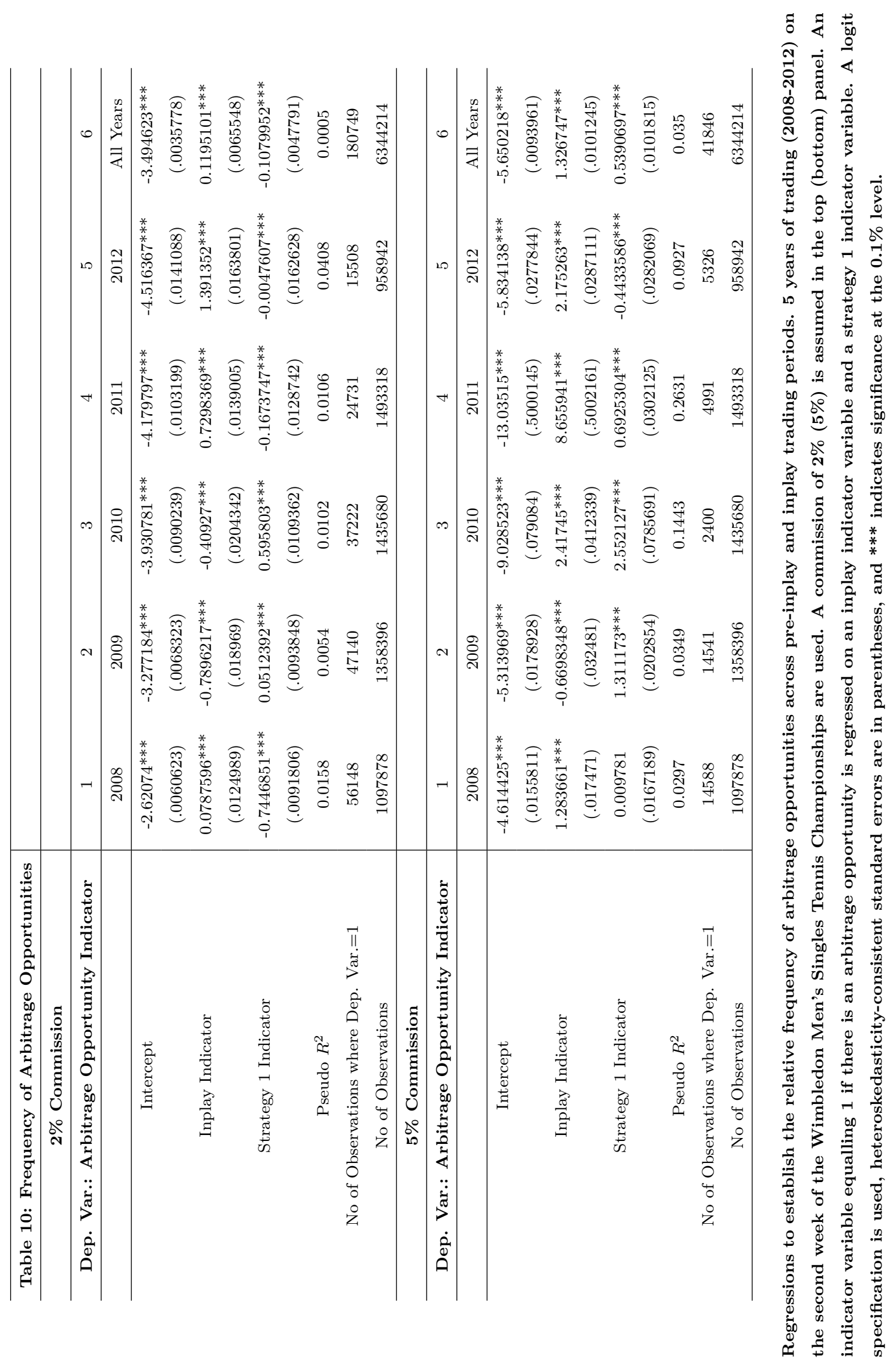


0

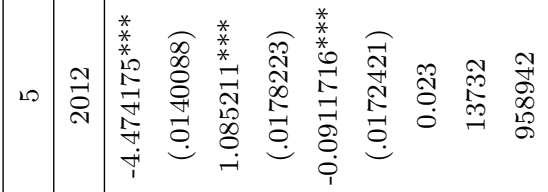

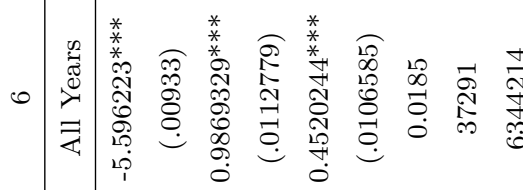

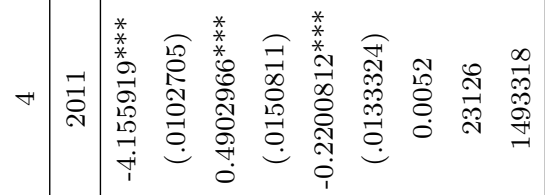

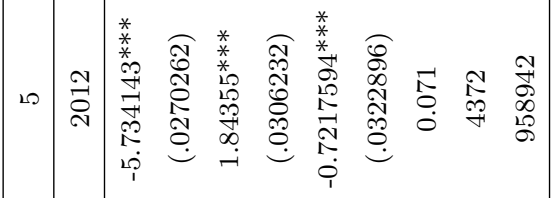

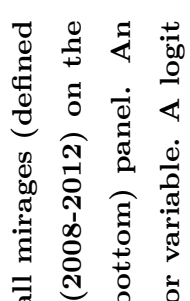

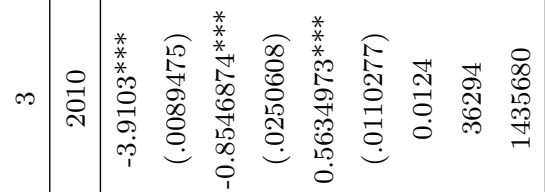

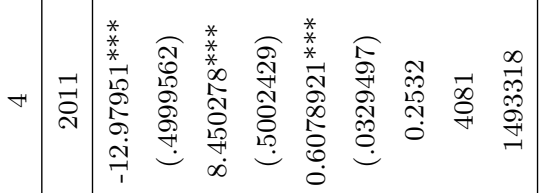

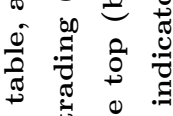

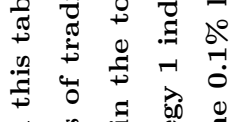
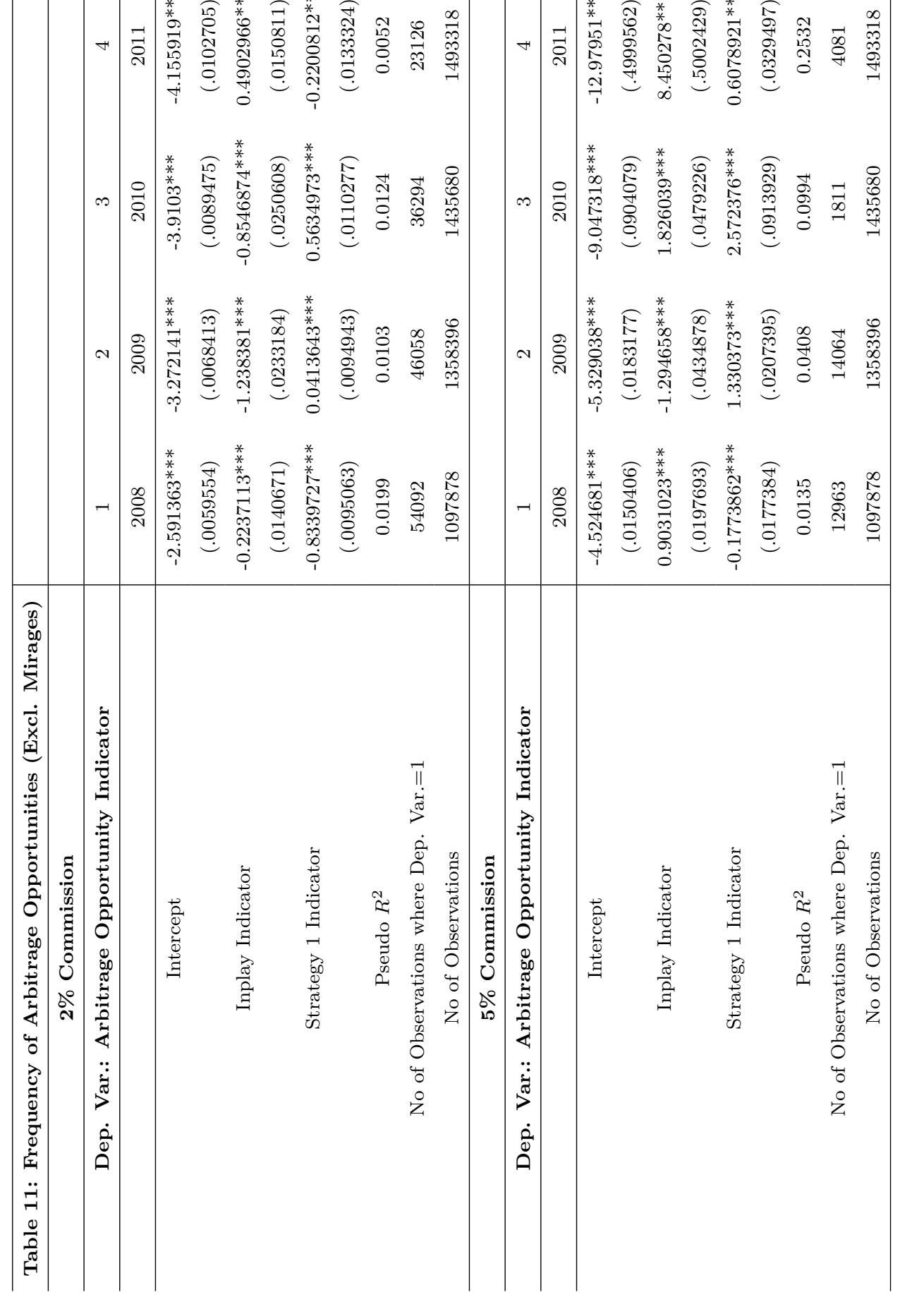

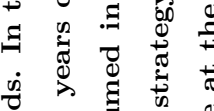

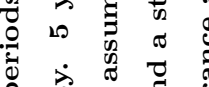

을

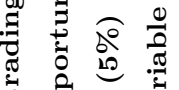

5 年

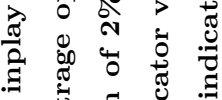

สัต

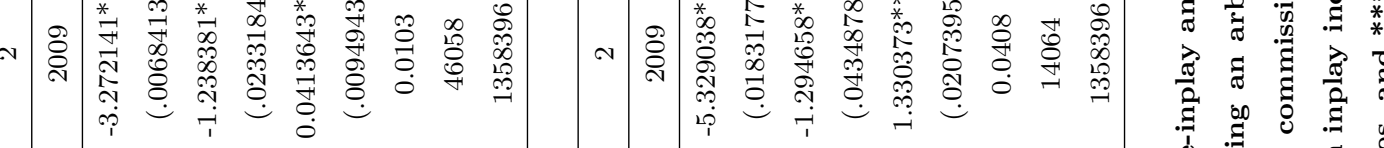

4 ส

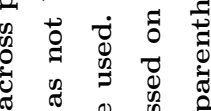

ชู

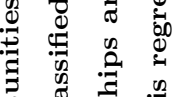

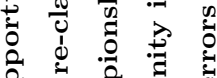

สั

可 0

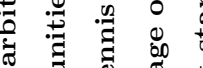

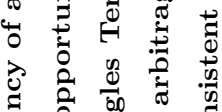

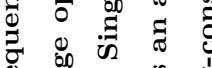

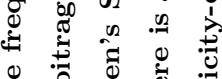

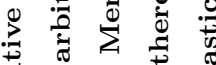

要要

要

-

की

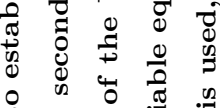

+10 y

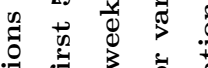

क

若 


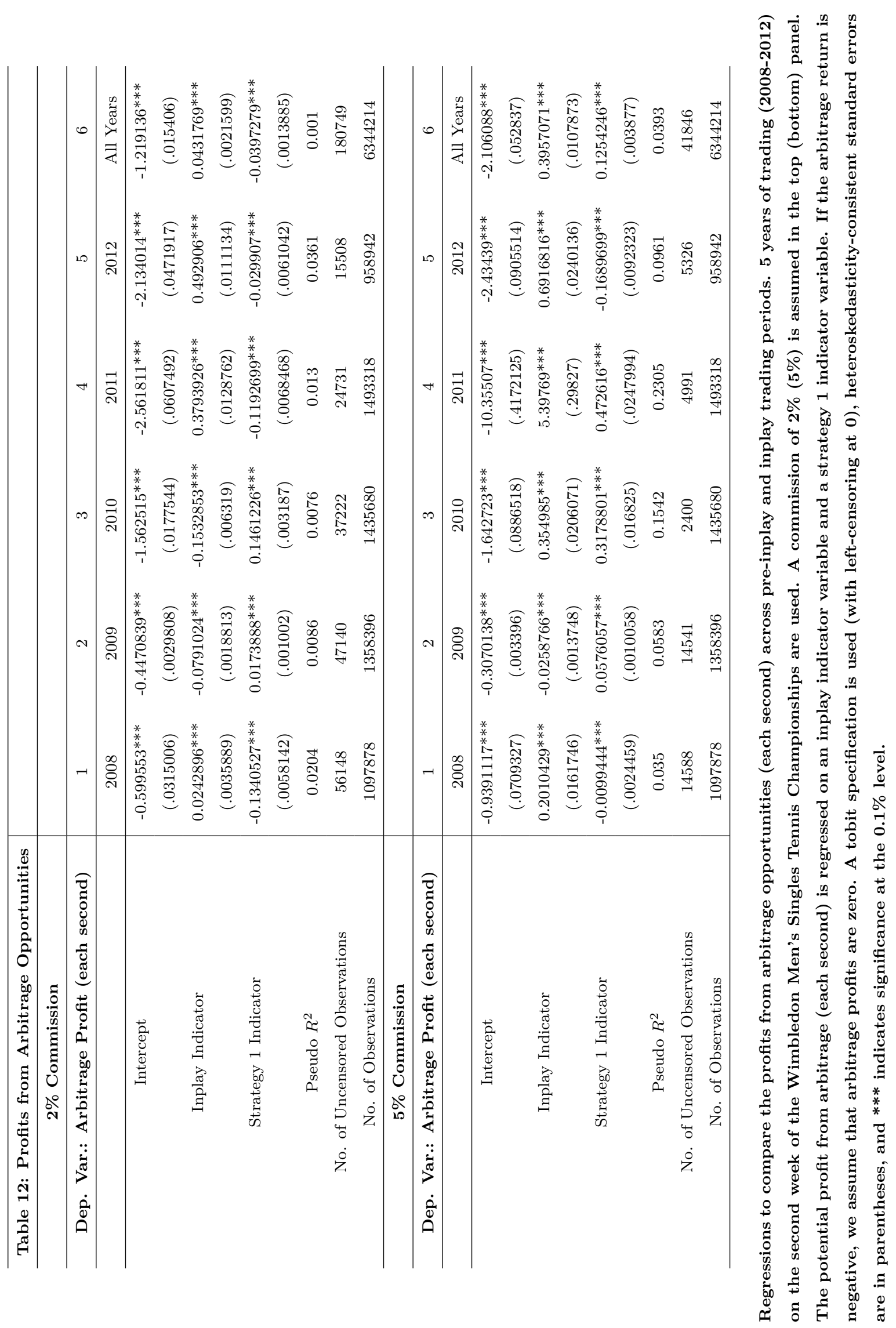


0

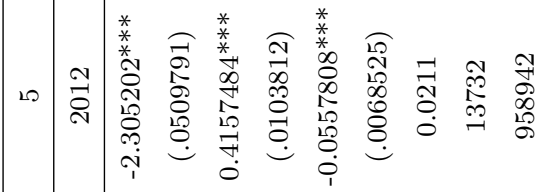

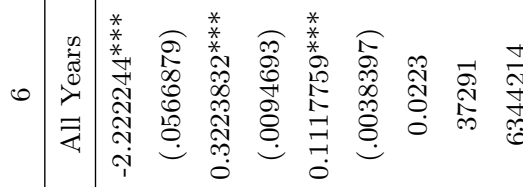

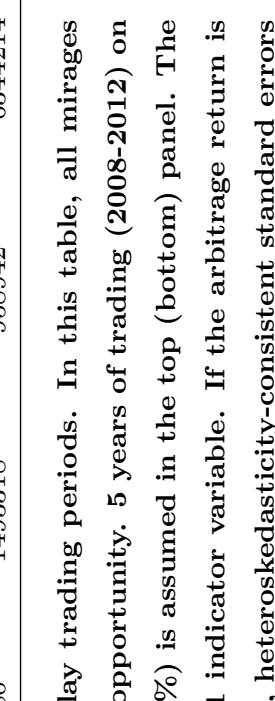

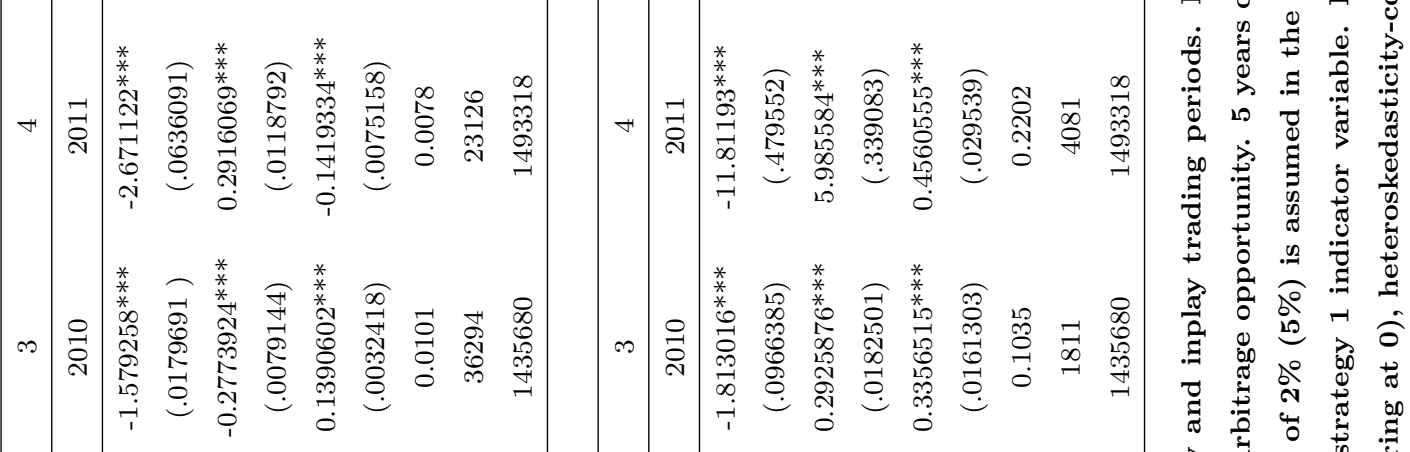

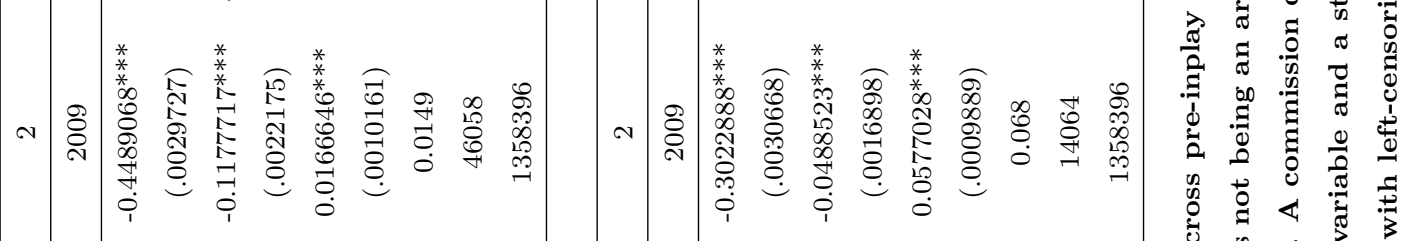

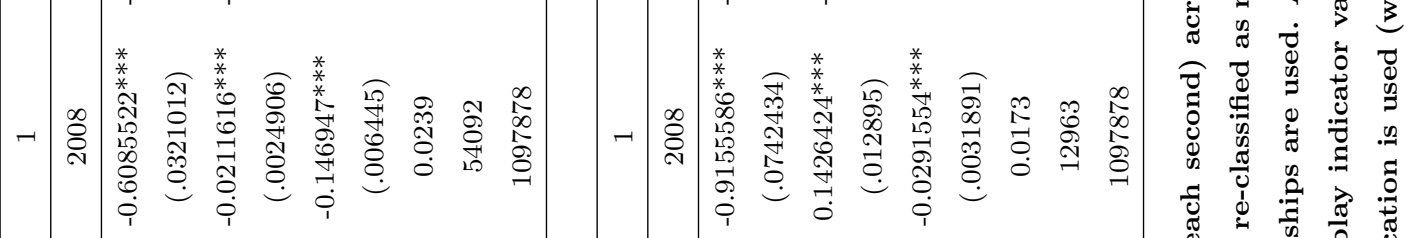

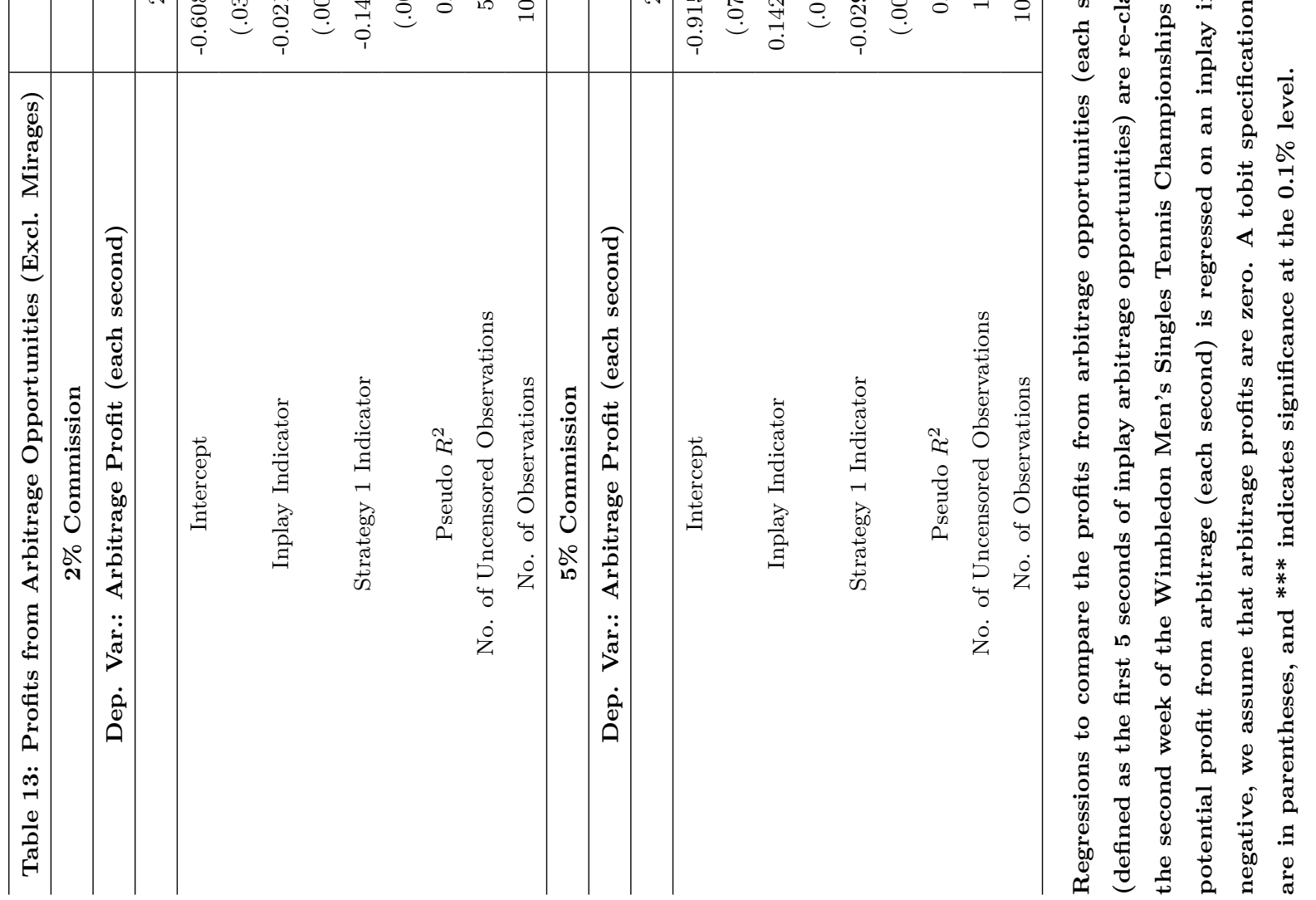

